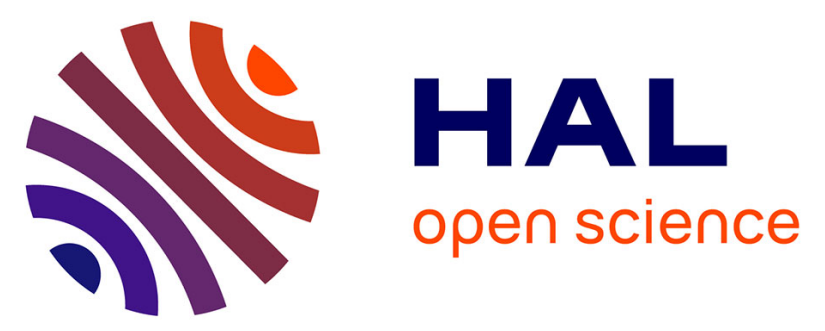

\title{
Conserved expression of alternative splicing variants of peroxisomal acyl-CoA oxidase 1 in vertebrates and developmental and nutritional regulation in fish
}

Sofia Morais, Anja Knoll-Gellida, Michèle André, Christophe Barthe, Patrick Babin

\section{To cite this version:}

Sofia Morais, Anja Knoll-Gellida, Michèle André, Christophe Barthe, Patrick Babin. Conserved expression of alternative splicing variants of peroxisomal acyl-CoA oxidase 1 in vertebrates and developmental and nutritional regulation in fish. Physiological Genomics, 2007, 28 (3), pp.239-252. 10.1152/physiolgenomics.00136.2006 . hal-02661138

\section{HAL Id: hal-02661138 \\ https://hal.inrae.fr/hal-02661138}

Submitted on 30 May 2020

HAL is a multi-disciplinary open access archive for the deposit and dissemination of scientific research documents, whether they are published or not. The documents may come from teaching and research institutions in France or abroad, or from public or private research centers.
L'archive ouverte pluridisciplinaire HAL, est destinée au dépôt et à la diffusion de documents scientifiques de niveau recherche, publiés ou non, émanant des établissements d'enseignement et de recherche français ou étrangers, des laboratoires publics ou privés. 
Sofia Morais, Anja Knoll-Gellida, Michèle André, Christophe Barthe and Patrick J. Babin

Physiol Genomics 28:239-252, 2007. First published Nov 7, 2006;

doi:10.1152/physiolgenomics.00136.2006

You might find this additional information useful...

Supplemental material for this article can be found at:

http://physiolgenomics.physiology.org/cgi/content/full/00136.2006/DC1

This article cites 63 articles, 28 of which you can access free at:

http://physiolgenomics.physiology.org/cgi/content/full/28/3/239\#BIBL

This article has been cited by 1 other HighWire hosted article:

High Transcript Level of Fatty Acid-Binding Protein 11 but Not of Very Low-Density Lipoprotein Receptor Is Correlated to Ovarian Follicle Atresia in a Teleost Fish (Solea senegalensis)

M. J Agulleiro, M. Andre, S. Morais, J. Cerda and P. J Babin

Biol Reprod, September 1, 2007; 77 (3): 504-516.

[Abstract] [Full Text] [PDF]

Updated information and services including high-resolution figures, can be found at:

http://physiolgenomics.physiology.org/cgi/content/full/28/3/239

Additional material and information about Physiological Genomics can be found at: http://www.the-aps.org/publications/pg

This information is current as of September 9, 2010 .

Physiological Genomics publishes results of a wide variety of studies from human and from informative model systems with techniques linking genes and pathways to physiology, from prokaryotes to eukaryotes. It is published quarterly in January, April, July, and October by the American Physiological Society, 9650 Rockville Pike, Bethesda MD 20814-3991. Copyright () 2007 by the American Physiological Society. ISSN: 1094-8341, ESSN: 1531-2267. Visit our website at http://www.the-aps.org/. 


\title{
CALL FOR PAPERS | Comparative Genomics
}

\section{Conserved expression of alternative splicing variants of peroxisomal acyl-CoA oxidase 1 in vertebrates and developmental and nutritional regulation in fish}

\author{
Sofia Morais, Anja Knoll-Gellida, Michèle André, Christophe Barthe, and Patrick J. Babin \\ Génomique et Physiologie des Poissons, Université Bordeaux 1, UMR NuAGe, 33405 Talence cedex, France
}

Submitted 27 June 2006; accepted in final form 6 November 2006

\begin{abstract}
Morais S, Knoll-Gellida A, André M, Barthe C, Babin PJ. Conserved expression of alternative splicing variants of peroxisomal acylCoA oxidase 1 in vertebrates and developmental and nutritional regulation in fish. Physiol Genomics 28: 239-252, 2007. First published November 7, 2006; doi:10.1152/physiolgenomics.00136.2006.-The acyl-coenzyme A oxidase 1 (ACOX1) catalyzes the first, rate-limiting step in peroxisomal $\beta$-oxidation of medium to very long straight-chain fatty acids. Zebrafish (Danio rerio) acoxl was characterized and compared with homologs from other sequenced genomes, revealing a remarkable conservation of structure in the vertebrate lineage. Strictly conserved regions of the deduced proteins included acyl-CoA oxidase and FAD binding domains, as well as a $\mathrm{COOH}$-terminal peroxisomal targeting signal. Whole mount in situ hybridization showed that zebrafish acoxl transcripts were diffusely distributed in early-stage embryonic cells, then discreetly expressed in the brain and widely present in the liver and intestine at later stages. An evolutionarily conserved alternative splicing of the corresponding acoxl primary transcript was identified in teleosts and tetrapods including mammals, giving rise, after exon skipping, to two splice variants, ACOX1-3I and ACOX1-3II. Real-time quantitative RT-PCR on zebrafish adult tissues indicated high levels of both variants in the liver, anterior intestine, and to a lesser extent, in the brain. However, the ACOX13II transcript variant was expressed seven times more in zebrafish brain than the ACOX1-3I variant. These data suggest a tissue-specific modulation of ACOX1 activity by exchanging exon 3 duplicated isoforms containing amino acid sequences that are potentially implicated in fatty acyl chain specificity. In addition, a significant pretranslational up-regulation of zebrafish and rainbow trout (Oncorhynchus mykiss) acoxl expression was observed in the anterior intestine after feeding. Taken together, these data indicate that ACOX1 alternative splicing isoforms play a key conserved role in the vertebrate fatty acid metabolism.
\end{abstract}

peroxisomal $\beta$-oxidation; zebrafish; fatty acid metabolism; nutrigenomics; intestine

PEROXISOMAL $\beta$-OXIDATION of fatty acids is a fundamental metabolic property of all eukaryotic cells, from bacteria to higher eukaryotes (27). This is not surprising, in view of the multiple essential roles played by fatty acids, including energy storage, signal molecules, precursors for steroid hormones, and structural components of membranes (45). However, while in plants and several fungi peroxisomal $\beta$-oxidation is the predominant fatty acid catabolic pathway $(17,27,45)$, in mammals, lipid breakdown requires the combined action of distinct mitochon-

Article published online before print. See web site for date of publication (http://physiolgenomics.physiology.org).

Address for reprint requests and other correspondence: P. J. Babin, Génomique et Physiologie des Poissons, Université Bordeaux 1, UMR NuAGe, 33405 Talence, France (e-mail p.babin@gpp.u-bordeaux1.fr). drial and peroxisomal $\beta$-oxidation systems. Mitochondrial $\beta$-oxidation is coupled to the respiratory chain, leading to the production of ATP. In contrast, in higher vertebrates, peroxisomal $\beta$-oxidation is incomplete and cannot fully degrade long-chain fatty acyl-CoAs. Its function is, thus, to shorten or convert fatty acids into a form that can be accepted by mitochondrial enzymes and exported into the mitochondria, where $\beta$-oxidation is completed $(27,49,62)$. The mitochondrial and peroxisomal $\beta$-oxidation systems consist of the same four consecutive steps but are catalyzed by different enzymes encoded by different genes, with partially overlapping substrates. However, very long-chain fatty acids (VLCFA; $\mathrm{C} \geq 20$ ) are almost exclusively $\beta$-oxidized in peroxisomes (see Ref. 49 for a review), which also oxidize long-chain dicarboxylic and branched-chain fatty acids (e.g., pristanic acid), $\mathrm{C}_{27}$ bile acid intermediates, eicosanoids (prostaglandins and leukotrienes), and some xenobiotics $(27,49)$. In addition, the peroxisomal $\beta$-oxidation system is implicated in the biosynthesis of polyunsaturated fatty acids, such as 22-carbon acids with their first double bond at position 4 (e.g., docosahexaenoic acid; DHA), in higher eukaryotes, which are believed to lack a $\Delta 4$ desaturase $(48,53)$.

Acyl-CoA oxidase (ACOX) belongs to the same flavoenzyme superfamily as mitochondrial acyl-CoA dehydrogenases (ACADs) and evolved from a common ancestral gene (27). These flavoenzymes contain one noncovalently bound FAD per subunit, catalyzing an analogous $\beta$-oxidation step in peroxisomes and mitochondria. Palmitoyl-CoA oxidase 1 (ACOX1) is a homodimer catalyzing the first, rate-limiting step in peroxisomal $\beta$-oxidation of fatty acids of all eukaryotes: acyl-CoAs longer than $\mathrm{C} 8$ are desaturated to 2-trans-enoylCoAs, donating electrons directly to molecular oxygen, thus generating $\mathrm{H}_{2} \mathrm{O}_{2}$ and energy, lost as heat $(27,49)$. The different substrate-specific ACOXs reflect the fact that mammalian peroxisomes oxidize a wide range of substrates. In rat peroxisomes, three ACOXs have been purified and characterized: palmitoyl-CoA, pristanoyl-CoA, and trihydroxycoprostanoylCoA oxidases (50). ACOX1 acts on CoA esters of medium to very long straight-chain fatty acids and prostaglandins and may be transcriptionally activated by treatment with peroxisome proliferators. Pristanoyl-CoA oxidase (ACOX3) oxidizes the CoA esters of 2-methyl-branched fatty acids as well as long straight-chain fatty acids and is not induced by peroxisome proliferators. Trihydroxycoprostanoyl-CoA oxidase (ACOX2) acts on CoA esters of di- and trihydroxycoprostanoic bile acid intermediates, is not inducible by peroxisome proliferators and is liver-specific $(27,49,50)$. In humans, only two acyl-CoA oxidases were originally identified, a palmitoyl-CoA oxidase 
and a branched-chain acyl-CoA oxidase, considered the homolog of rat $\operatorname{ACOX} 2(3,6,60)$. However, a gene corresponding to $\mathrm{ACOX} 3$ was later found in human, and a human liver cDNA encoding a protein showing $75 \%$ amino-acid identity with rat pristanoyl-CoA oxidase was isolated (59).

Many severe pathological conditions described in mammals result either from a generalized impairment of peroxisome assembly (e.g., Zellweger cerebro-hepato-renal syndrome), defects of a limited number of peroxisomal functions (e.g., pseudo-Zellweger syndrome), or a single peroxisomal function or enzyme deficiency (e.g., X-linked adrenoleukodystrophy, or pseudoneonatal adrenoleukodystrophy, caused by ACOX deficiency) $(10,13,49,52)$. These syndromes result in a massive accumulation of either VLCFA or bile acid intermediates, or both, depending on whether the whole peroxisome is defective or which single enzyme is deficient $(10,27,52)$. In addition, fibroblasts without peroxisomes from patients with Zellweger syndrome lose the capacity to convert $3-{ }^{14} \mathrm{C}$-labeled $24: 5-$ $9,12,15,18,21$ to DHA $(32,55)$.

The cDNA encoding mammalian ACOX1 has been cloned in various species and its open reading frame (ORF) encodes a protein of 662, 661, and 660 amino acids in koalas, rats, and humans, respectively $(13,31,37,41,61)$. The structure of the corresponding gene has an extremely high resemblance, consisting of 14 exons and 13 introns, with essentially identical intron positions and exon lengths (except exon 14) $(41,61)$. The average homology between rats and humans is $85 \%$ at the cDNA nucleotide level and $89 \%$ in terms of amino acid sequence (13). In mammals, there are two species of cDNA with different nucleotide sequences for exon 3 (3I and 3II), resulting in the production of two ACOX1 proteins by alternative splicing $(31,37,61)$. These two alternative exons contain an identical number of nucleotides and share $55 \%$ and $52 \%$ identity at the nucleotide level in rats and humans, respectively, while each of the human sequences has a $91 \%$ identity with its rat counterpart $(13,31,41)$.

In addition to studies of mammalian ACOX, work has also been conducted on lower eukaryotes, describing ACOX cDNAs and proteins in Candida tropicalis (three genes: POX2, POX4 and POX5) $(39,40)$ and Saccharomyces cerevisiae yeasts ( $P O X 1$ gene) (9), as well as in several plants, including Arabidopsis (two genes: AtACXI and AtACX2) $(17,45)$ and pumpkins (16). However, there are few data concerning the molecular characterization of ACOXs in species between lower eukaryotes and mammals, particularly nontetrapode vertebrate species. Therefore, the first objective of this study was to characterize the structure of zebrafish (Danio rerio) acoxl and compare it with homologs identified in other sequenced genomes. The tissue distribution of acoxl transcripts from the early embryonic to adult stages and the alternative splicing variants of primary transcripts including their differential expression in larval and adult tissues were investigated. Finally, the effect of feeding on the following was examined: 1) zebrafish transcript variant levels in larvae and in the intestine and liver of adults and 2) acoxl transcript levels in the anterior intestine of juvenile rainbow trout (Oncorhynchus mykiss).

\section{MATERIALS AND METHODS}

Animals. Adult zebrafish (D. rerio) were purchased from local commercial sources. Embryos and larvae were obtained by natural mating and raised at $28^{\circ} \mathrm{C}$, as described in http://zfin.org/zf_info/ zfbook/cont.html. In some cases, larvae were raised in water containing 0.15 mM 1-phenyl-2-thio-urea (PTU; Sigma Chemical, St Louis, MO) to prevent pigment formation. Developmental stages were recorded as hours or days postfertilization (hpf or dpf), as described by Kimmel et al. (23). Juvenile trout (O. mykiss) were reared in duplicate tanks (100 fish/tank; initial weight $139 \mathrm{~g}$ ) at the French National Institute for Agricultural Research (INRA) experimental rearing facilities (Donzacq, France), at a temperature of $18^{\circ} \mathrm{C}$ under natural photoperiod in spring, for a period of $7 \mathrm{wk}$.

Sequence sources and analyses. Vertebrate genomic sequences used, including zebrafish acoxl, were downloaded from the Ensembl genome database (http://www.ensembl.org/). Entrez Gene references (http://www.ncbi.nlm.nih.gov/entrez/) were GeneID:51 for human (Homo sapiens), GeneID:50681 for rat (Rattus norvegicus), and GeneID:417366 for chicken (Gallus gallus) genes. Ensembl accession number ENSXETG00000012601 (UniGene Str.15330) was used for Xenopus tropicalis gene. Deduced protein sequences were extracted from GenBank (gb) (http://www.ncbi.nlm.nih.gov/) or UniProt (up) (http://www.ebi.uniprot.org/index.shtml) databases or, in a few cases, deduced from Ensembl genomic sequences (en) or TIGR (ti) (http:// compbio.dfci.harvard.edu/tgi/). Accession numbers were gb NP_009223 or up Q15067 for human 3I (Hum3I), gb NP_004026 for human 3II, gb NP_059036 for rat 3I, gb 20663871 for rat 3II, up Q9R0H0 for mouse (Mus musculus) 3I, gb CD737325 for chicken 3I, gb NP_001006205 for chicken 3II, en AAH63727 for X. tropicalis 3I, gb NP_001015762 for X. tropicalis 3II, gb AAH63727 for Xenopus laevis 3I, gb AAI08648 for X. laevis 3II, gb AAH83524 for zebrafish (D. rerio) 3I, gb AAH97101 for zebrafish 3II, gb DT209103 for fathead minnow (Pimephales promelas) 3I, gb DT203829 for fathead minnow 3II, gb CAG10777 for freshwater pufferfish (Tetraodon nigroviridis) 3I, en GSTENP00032511001 for freshwater pufferfish 3II, partial TIGR sequences ti TC6052 for Japanese pufferfish (Takifugu rubripes) 3I, partial sequences ti TC5713 for Japanese pufferfish 3II, and partial sequence gb BX085367 for rainbow trout (O. mykiss), ACOX1 isoforms. Accession numbers were up Q99424 for human, up Q9QXD1 for mouse, gb XP_414406 for chicken, and gb AAH68891 for X. laevis, ACOX2 deduced proteins. Accession numbers were up 015254 for human, up Q9EPL9 for mouse, en ENSGALP00000025093 for chicken, en ENSXETP00000043896 for Xenopus tropicalis, gb CAF91771 for Tetraodon nigroviridis, and gb NP_998312 for zebrafish, ACOX3 deduced proteins. Accession numbers were en ENSCING00000001357 and en ENSCINP00000020743 for Ciona intestinalis, GeneID: 662475 and gb XP_973660 for Tribolium castaneum, GeneID: 37028 and gb AAD38617 for Drosophila melanogaster, GeneID: 827381 and gb NP_567513 for Arabidopsis thaliana, GeneID: 852667 and gb CAG80078.1 for Yarrowia lipolytica, and GeneID: 852667 and gb CAA96918 for S. cerevisiae, ACOX homologous gene and deduced protein sequences.

Nucleotide or protein sequences were aligned using LALIGNn, LALIGN-p, and ClustalW (http://bioinfo.hku.hk/). Phylogenetic analyses were conducted using MEGA version 3.1 (26).

Zebrafish embryonic developmental stages. Embryos were collected at different stages of development: $2-2.5 \mathrm{hpf}$ ( $<32$ cells), 3-4 hpf, 5 hpf (50\% epiboly), 8 hpf (75\% epiboly), 9-10 hpf $(90 \%$ epiboly), 11-12 hpf (2-6 somites), 16-18 hpf, 24 hpf, 2 dpf, 3 dpf, 4 $\mathrm{dpf}$, and $5 \mathrm{dpf}$. The animals used for whole mount in situ hybridization were subjected to PTU treatment from fertilization and were, therefore, not pigmented. The samples were fixed in $4 \%$ paraformaldehyde (PFA) overnight at $4^{\circ} \mathrm{C}$, rinsed three times in phosphate-buffered saline (PBS: $137 \mathrm{mM} \mathrm{NaCl}, 2.7 \mathrm{mM} \mathrm{KCl}, 0.02 \mathrm{M} \mathrm{PO}_{4}$ ), then rinsed and transferred into $100 \%$ methanol, and stored at $-20^{\circ} \mathrm{C}$ until analysis.

Zebrafish nutritional experiments and tissue sampling. Zebrafish adults were fed TetraMin flakes (Tetra, Melle, Germany) containing $48 \%$ proteins, $8 \%$ lipids, $11 \%$ ash, $2 \%$ fibers, and $6 \%$ moisture, while larvae were reared on dried chicken egg-yolk powder from first feeding ( $5 \mathrm{dpf}$ ) to $15 \mathrm{dpf}$. A single meal was given in the morning. 
Zebrafish larvae were sampled at 5, 8, and $15 \mathrm{dpf}$, corresponding to different nutritional developmental stages. At $5 \mathrm{dpf}$, the larvae are at the beginning of the mixed endotrophic-exotrophic period, which ends at $\sim 8 \mathrm{dpf}$ (unpublished results), while at $15 \mathrm{dpf}$ larvae depend exclusively on exogenous nutrients. On the day preceding the nutritional trials, larvae and adults were divided into two groups and transferred into containers with water but no food. After $\sim 18 \mathrm{~h}$ (larvae) or $22 \mathrm{~h}$ (adults) food deprivation, one group of larvae or adults was fed for 2-2.5 h, while the second group continued to fast. After feeding, the larvae were transferred into clean water (to eliminate any remaining food), and samples of 25 larvae (at 5 and $8 \mathrm{dpf}$ ) or 20 larvae (at $15 \mathrm{dpf}$ ) were immediately frozen in liquid nitrogen or fixed in $4 \%$ PFA, as described above. The frozen larvae for real-time quantitative RT-PCR (qPCR) were stored at $-80^{\circ} \mathrm{C}$ until RNA extraction. The fasting group was treated in a similar way. Two separate batches were used as sources of 5 and $8 \mathrm{dpf}$ larvae. After feeding, the adults were dissected, and six separate samples of liver and anterior intestine were isolated, immediately frozen in liquid nitrogen, and stored at $-80^{\circ} \mathrm{C}$. The fasting group was treated similarly, and, in addition to the liver and anterior intestine, six separate samples were collected from brains, one from ovaries, and one from testicles, as well as one heart sample from a pool of six animals and one kidney sample from a pool of four animals. All samples, except heart, kidney, and ovary tissues, were collected from male organisms.

Trout nutritional experiments. Trout were hand-fed $1.5 \%$ of their body weight twice a day, and the ration was adjusted once a week, after the fish were weighed. Fish diet contained $90 \%$ dry matter (DM), $50 \%$ crude protein DM, 25\% crude lipid DM, and 14\% starch DM and supplied $24 \mathrm{~kJ} / \mathrm{g}$ DM (44). Eight anterior intestine samples were collected from fed and fasting trout, immediately frozen in liquid nitrogen, and kept at $-80^{\circ} \mathrm{C}$ pending RNA extraction. The fasting group was deprived of food for 3 days prior to sampling, while the intestines of the fed group, also previously starved for 3 days, were sampled $8 \mathrm{~h}$ after feeding, shortly after the postprandial peak of triacylglycerol absorption (44).

Whole mount in situ hybridization. Whole mount in situ hybridization was carried out on zebrafish embryos and larvae sampled and fixed in 4\% PFA, as described above. A clone purchased from the German Resource Center for Genome Research (RZPD), Berlin, Germany (IMAG p998 LO48992), corresponding to GenBank database dbEST zebrafish clone gb BF717863.1, was used to generate the RNA probes. The sense (LO4)S 5'-GACACAAAGCAGAAGGCACG-3' and antisense (LO4)AS 5'-GTAGGTCAAGGGGCTCTGG-3' primers were designed from this clone. A PCR was performed with $1.5 \mu \mathrm{l}$ cDNA, $0.5 \mu \mathrm{M}$ of each primer, $0.25 \mathrm{mM}$ dNTPs (each), $2.5 \mathrm{mM}$ $\mathrm{MgCl}_{2}$, and 0.05 units/ $\mu \mathrm{l}$ Taq DNA polymerase (Promega, Charbonnières les Bains, France). The PCR thermal profile included one denaturing step at $94^{\circ} \mathrm{C}$ for 4 min followed by 30 cycles at $94^{\circ} \mathrm{C}$ for $30 \mathrm{~s}, 59^{\circ} \mathrm{C}$ for $30 \mathrm{~s}, 72^{\circ} \mathrm{C}$ for $45 \mathrm{~s}$, and one cycle at $72^{\circ} \mathrm{C}$ for $3 \mathrm{~min}$. The PCR fragment was purified (Agar ACE, Promega, France), then subcloned into pGEM-T Easy vector kit (Promega, France) and sequenced (Eurogentec, Belgium). A second PCR was performed with $2.5 \mu \mathrm{l}$ (=5 ng) vector cDNA, using the T7 and SP6 universal primers, under the same conditions described above, except that the primer annealing temperature $(\mathrm{Tm})$ in the thermal profile was $56^{\circ} \mathrm{C}$. The T7/SP6 fragment was purified (NucleoSpin Extract II kit; MachereyNagel, Hoerdt, France), and a third PCR series was performed to produce the cDNA fragments used as templates for generating the RNA probes. As the fragment was sense-orientated in the vector, the PCR template for the sense probe was produced using T7 universal primer and (LO4)AS primer, while the PCR template for the probe antisense was produced using SP6 universal primer and (LO4)S primer. PCR was carried out using $1.5 \mu \mathrm{l} \mathrm{cDNA}$ (=3 ng), under the conditions described above, with a Tm of $56^{\circ} \mathrm{C}$. Both antisense and sense digoxigenin (DIG)-labeled RNA probes were synthesized using the DIG RNA labeling kit (SP6/T7) (Roche Diagnostics, Meylan, France), following the manufacturer's instructions. Probe length was
$357 \mathrm{bp}$ and was able to hybridize to 3-I and 3-II splicing transcript variants. The protocol for in situ hybridization is described in detail in Cotto et al. (8). However, prehybridization and hybridization were conducted at $60^{\circ} \mathrm{C}$ for 5,8 , and $15 \mathrm{dpf}$ larvae and at $62^{\circ} \mathrm{C}$ for the embryonic stages. The posthybridization stringent baths were at hybridization temperature, except for the last two baths in $0.2 \times \mathrm{SSC}$ Tween (30 min each), maintained at 57 and $59^{\circ} \mathrm{C}$ for larvae and embryos, respectively. On the other hand, the hybridization buffer contained $50 \%$ formamide, instead of the $65 \%$ used by Cotto et al. (8). Another difference was that embryos and larvae were incubated in preabsorbed sheep anti-DIG-AP Fab (Roche Diagnostics, Meylan, France) fragments at $1: 5,000$ dilution overnight, at $4^{\circ} \mathrm{C}$. The antibody was rinsed in six PBS-Tween baths for 30 min each time. The coloration reaction was stopped after $6 \mathrm{~h}$ for $5 \mathrm{dpf}$ and $8 \mathrm{dpf}$ larvae, $8 \mathrm{~h} 30 \mathrm{~min}$ for $15 \mathrm{dpf}$ larvae, and between $3 \mathrm{~h} 30 \mathrm{~min}$ and $7 \mathrm{~h} 30 \mathrm{~min}$ for embryos, depending on the stage. The resulting dark blue to purple color indicates the localization of transcripts. After coloration, embryos and larvae were re-fixed in 4\% PFA and gradually transferred into glycerol.

Extraction of total RNA and reverse transcription. Total zebrafish RNAs were extracted using the NucleoSpin RNA II extraction kit (Macherey-Nagel, Hoerdt, France) according to the manufacturer's instructions. Trout total RNAs were extracted using WIZ RNA isolation reagent without DNase treatment (Ambion, Huntingdon, UK). The total RNA was checked for integrity by ethidium bromide staining in agarose borax gels and quantified using a NanoDrop ND-1000 spectrophotometer (Nyxor Biotech, Paris, France). Reverse transcriptions (RT) were performed with $1 \mu \mathrm{g}$ total RNAs using the StrataScript first-strand cDNA synthesis kit (Stratagene, Amsterdam, The Netherlands), with an oligo(dT) primer, according to the manufacturer's instructions. The reaction mixture $(20 \mu \mathrm{l}$ for larvae and trout; $50 \mu \mathrm{l}$ for adult zebrafish tissues) was incubated at $42^{\circ} \mathrm{C}$ for 30 min, followed by $1 \mathrm{~h} 30 \mathrm{~min}$ at $45^{\circ} \mathrm{C}$, and the reaction was inactivated at $90^{\circ} \mathrm{C}$ for $5 \mathrm{~min}$. Two RTs and one RT negative control (without reverse transcriptase) were carried out on each sample.

$q P C R$. Transcripts were amplified using the MX 3000P QPCR thermal cycler instrument (Stratagene, Amsterdam, The Netherlands). The qPCR amplifications were carried out in a final volume of $20 \mu \mathrm{l}$ with $10 \mu \mathrm{l}$ Brilliant SYBR Green QPCR master mix (Stratagene), 0.5 $\mu \mathrm{M}$ oligodeoxyribonucleotide primers, and $2 \mu \mathrm{l}$ diluted $(1 / 20) \mathrm{ze}-$ brafish larvae cDNA, $1.5 \mu$ diluted (1/9) adult zebrafish liver and anterior intestine cDNA, 4 or $8 \mu$ l (depending on the gene) diluted (1/9) adult zebrafish brain cDNA, and $4 \mu \mathrm{l}$ diluted (1/10) trout intestine cDNA. In each run, $4 \mu$ l of serial dilutions of cDNA with six or seven dilution points were included, using a pool of cDNA from the samples being quantified, to generate standard curves representing cycle threshold $\left(\mathrm{C}_{\mathrm{T}}\right)$ value as a function of the logarithm of the number of copies generated. Amplifications were carried out with a systematic negative control (NTC-nontemplate control, containing no cDNA). Each RT from the same sample was amplified in triplicate and, as no significant differences were found in $\mathrm{C}_{\mathrm{T}}$, the two RT products were pooled. For zebrafish, two pairs of primers were designed, to quantify the expression of both acoxl splicing variant transcripts independently, while, for trout, a single pair of primers was designed to amplify the acoxl transcript. To standardize the results by eliminating variations in mRNA and cDNA quantity and quality among samples, the transcript level of several normalizing genes was also quantified. Elongation factor $1 \alpha(e f 1 \alpha)(14)$ and 2-peptidylprolyl isomerase A (ppia2) (12) were chosen as normalizing genes for zebrafish. $\beta$-actinl and efl $\alpha$ were used as control genes for rainbow trout. The sequence, design details, size of the fragment produced, and $\mathrm{Tm}$ of the primer pairs used are described in Table 1 . The qPCR profiles contained an initial denaturation step at $95^{\circ} \mathrm{C}$ for $10 \mathrm{~min}$, followed by $30-40$ cycles: $30 \mathrm{~s}$ at $95^{\circ} \mathrm{C}, 30 \mathrm{~s}$ at the specific primer pair $\mathrm{Tm}$ (see Table 1), and $30 \mathrm{~s}$ at $72^{\circ} \mathrm{C}$. After the amplification phase, $1 \mathrm{~min}$ incubation at $95^{\circ} \mathrm{C}$ and $30 \mathrm{~s}$ at $55^{\circ} \mathrm{C}$ was followed by amp up to $95^{\circ} \mathrm{C}$, at $0.01^{\circ} \mathrm{C} / \mathrm{s}$, where data were collected in continuum, to 
Table 1. Sequence, design, size of the fragment produced, and Tm of the primer pairs used for real-time quantitative PCR determinations of the transcript level of several zebrafish and trout genes

\begin{tabular}{|c|c|c|c|c|c|c|c|}
\hline Species & Gene & Primer Name & Primer Sequence & Primer Position & $\begin{array}{l}\text { Fragment, } \\
\text { bp }\end{array}$ & $\mathrm{Tm},{ }^{\circ} \mathrm{C}$ & $\begin{array}{l}\text { Reference } \\
\text { Sequence }\end{array}$ \\
\hline Zebrafish & acoxl, $3 I$ & $\begin{array}{l}\text { Acox-3I-ZF-S1 } \\
\text { Acox-3I-ZF-AS1 }\end{array}$ & $\begin{array}{l}\text { 5' - CTACAAGACTGTTGTGAGGGGTGTAT - 3' } \\
5^{\prime} \text { - ACATATGGAATGACTCAGCTAATGG - 3' }\end{array}$ & $\begin{array}{l}\text { 328-353 bp, exon 2/3I } \\
440-464 \mathrm{bp} \text {, exon 3I }\end{array}$ & 137 & 62 & NM_001005933 \\
\hline Zebrafish & acoxl, $3 I I$ & $\begin{array}{l}\text { Acox-3II-ZF-S1 } \\
\text { Acox-3II-ZF-AS2 }\end{array}$ & $\begin{array}{l}\text { 5' - TCCTACAAGACCTGTGTTCATCG - 3' } \\
\text { 5'- TGCCAATAATCTCCAAGTTCCAT - 3' }\end{array}$ & $\begin{array}{l}304-326 \mathrm{bp} \text {, exon 2/3II } \\
426-448 \mathrm{bp} \text {, exon 3II }\end{array}$ & 145 & 62 & ВС097101 \\
\hline Zebrafish & $e f l \alpha$ & $\begin{array}{l}\mathrm{EF} 1 \alpha-2^{*} \\
\mathrm{EF} 1 \alpha-3^{*}\end{array}$ & $\begin{array}{l}\text { 5' - CGTCTGCCACTTCAGGATGTG - 3' } \\
\text { 5' - ACTTGCAGGCGATGTGAGCAG - 3' }\end{array}$ & $\begin{array}{l}798-819 \text { bp, exon } 5 \\
1153-1174 \text { bp, exon } 7\end{array}$ & 376 & 63 & X77689 \\
\hline Zebrafish & ppia2 & $\begin{array}{l}\text { Ppia2-ZF-S1 } \\
\text { Ppia2-ZF-AS1 }\end{array}$ & $\begin{array}{l}\text { 5' - GGGTGGTAATGGAGCTGAGA - 3' } \\
\text { 5' - AATGGACTTGCCACCAGTTC - 3' }\end{array}$ & $\begin{array}{l}317-336 \text { bp, exon } 1 / 2 \\
476-495 \mathrm{bp}, \text { exon } 4\end{array}$ & 179 & 60 & AY391452 \\
\hline Trout & acoxl & $\begin{array}{l}\text { Acox-T-S } \\
\text { Acox-T-AS }\end{array}$ & $\begin{array}{l}5^{\prime}-\text { GATCTCAGACCCTGAGGAA - } 3^{\prime} \\
5^{\prime}-\text { TCTGTATGGGACTGACCG - 3' }\end{array}$ & $\begin{array}{l}267-285 \mathrm{bp} \dagger \\
462-479 \mathrm{bp} \dagger\end{array}$ & 213 & 60 & BX085367 \\
\hline Trout & $e f l \alpha$ & $\begin{array}{l}\text { EF1-T-S } \\
\text { EF1-T-AS }\end{array}$ & $\begin{array}{l}5^{\prime}-\text { TCCTCTTGGTCGTTTCGCTG - 3' } \\
5^{\prime}-\text { ACCCGAGGGACATCCTGTG - } 3^{\prime}\end{array}$ & $\begin{array}{l}1313-1332 \mathrm{bp} \\
1453-1471 \mathrm{bp}\end{array}$ & 159 & 59 & AF498320 \\
\hline Trout & $\beta$-actinl & $\begin{array}{l}\text { Bact1-T-S1 } \\
\text { Bact1-T-AS1 }\end{array}$ & $\begin{array}{l}\text { 5' - CTTCCTCGGTATGGAGTCTT - 3' } \\
\text { 5' - ATGATCTTGATCTTCATGGTG - 3' }\end{array}$ & $\begin{array}{l}856-875 \mathrm{bp} \\
1030-1050 \mathrm{bp}\end{array}$ & 195 & 59 & AJ438158 \\
\hline
\end{tabular}

The reference sequences are from the GenBank database (http://www.ncbi.nlm.nih.gov/). *Gao et al. (14). †Primer Acox-T-S and Acox-T-AS were positioned on each side of the trout sequence corresponding to zebrafish exon 3, after multiple alignments with zebrafish clones corresponding to both acoxl transcript splicing variants. The amino acid alignment of the region corresponding to exon 3 made it possible to identify the trout clone as a 3I isoform (presenting all the amino acid marker residues for this isoform, see Fig. 2). Tm, annealing temperature.

obtain a dissociation curve. The qPCR product sizes were checked on $2 \%$ agarose gel. No amplification was observed in RT negative controls and no primer-dimer formation occurred in the NTC. qPCR efficiency was over $95 \%$ and the correlation coefficient was $>0.97$ for each run. Interassay reproducibility between quantitative analyses was assessed in three runs for each target gene. Six (zebrafish) or eight (trout) independent samples, each representing a pool of larvae or tissues (liver, anterior intestine, and brain) from individual adults, were tested in duplicate. Zebrafish heart (pool from six animals), kidney (pool from four animals), ovary, and testicle samples were subjected to a single determination in duplicate.

Statistical analysis. Data are presented as means \pm SD. Variations in acoxl transcript levels (normalized by reference genes) between fed and fasting fish, as well as between the two acoxl transcript variants in zebrafish brain, liver, and anterior intestine, were analyzed for statistical significance using a Mann-Whitney test (GraphPad InStat v3.5, GraphPad Software). The significance level was set at 0.05 .

\section{RESULTS}

Molecular characterization of zebrafish acoxl and its comparison with vertebrate tetrapod sequences. The structure of zebrafish acoxl was deduced from genomic sequences registered in the Ensembl genome database after comparison with the respective cDNA reference sequences. The zebrafish acox 1 spans $\sim 14 \mathrm{~kb}$, containing 14 exons and 13 introns. Exons 3I and 3II were counted only once as initially defined with rat Acoxl (41). The sequences at the intron-exon boundaries were consistent with the consensus intron/exon splice junction rule (GT/AG) (data not shown). This gene corresponds to ZFIN (http://zfin.org/cgi-bin/webdriver?MIval=aa-ZDB_home.apg) ID:ZDB-GENE-041010-219 or Entrez Gene ID:449662. Comparison with acoxl genomic sequences registered in the Ensembl genome database for humans, rats, chickens, and $X$. tropicalis revealed an extremely highly conserved gene structure. Almost all exons were of identical length, except exon 10 in zebrafish, which has $177 \mathrm{bp}$ instead of $180 \mathrm{bp}$ in the other species, exon 14 in humans, which has 48 bp instead of $51 \mathrm{bp}$ in the other species analyzed, and exon 1 of chicken, which has an extra ATG codon at the start of the exon (data not shown). There are, thus, very slight differences, resulting in minor differences in ACOX1 proteins, which are 660 amino acid long in zebrafish and humans, 661 amino acids in rats and $X$. tropicalis, and 662 amino acids in the chicken. Alignments of zebrafish ACOX1 with their tetrapod homologs (Fig. 1 shows alignment with rat sequence only) revealed an overall identity of $\sim 70 \%$ at the amino acid level, with perfectly conserved acyl-CoA oxidase and FAD binding domains, in positions 174-179 and 396-401, respectively. The Glu421 catalytic active site and the consensus sequence for the Ser/Thr dehydratase pyridoxal-phosphate attachment site, as well as the $\mathrm{COOH}$-terminal tripeptide peroxisomal targeting signal (SKL) were also conserved.

The dbEST database (http://www.ncbi.nlm.nih.gov/dbEST/ index.html) was searched for the complete cDNA and amino acid sequences of zebrafish ACOX1. Three reference EST sequences containing the complete coding sequence of ACOX1 were found in UniGene Dr.36780, under accession numbers gb BC083524.1, gb NM_001005933.1, and gb BC097101.1. The first two cDNA sequences were identical, spanning 2,615 $\mathrm{bp}$, with the first ATG codon (position 68-70 bp) initiating an ORF of $1,983 \mathrm{bp}$, including the TAA stop codon (position 2,048-2,050 bp). A consensus sequence for polyadenylation (AATAAA) was located 19 nucleotides upstream from the poly(A) tail, at 2,568-2,573 bp. The third reference sequence, gb BC097101.1, spanning 2,590 bp, encodes an ORF of 1,983 $\mathrm{bp}$, from the ATG codon at 46-48 bp to the TAA stop codon, at 2,026-2,028 bp. The polyadenylation signal is located 23 nucleotides upstream of the poly(A) tail, at 2,547-2,552 bp. All reference sequences encode proteins of 660 amino acid residues. Alignment of the first two EST sequences with the third one revealed that they were not aligned in a region of 130 nucleotides, from 270 to $399 \mathrm{bp}$, numbered from the first position of the initiator ATG codon. This small nucleotide region that did not align between the transcripts extracted from expression databases was found to be part of two sequences for exon 3 (3I and 3II), which may be alternatively spliced to produce two transcript variants (Fig. 2A). There was $57.1 \%$ identity between the two zebrafish exon 3 nucleotide se- 


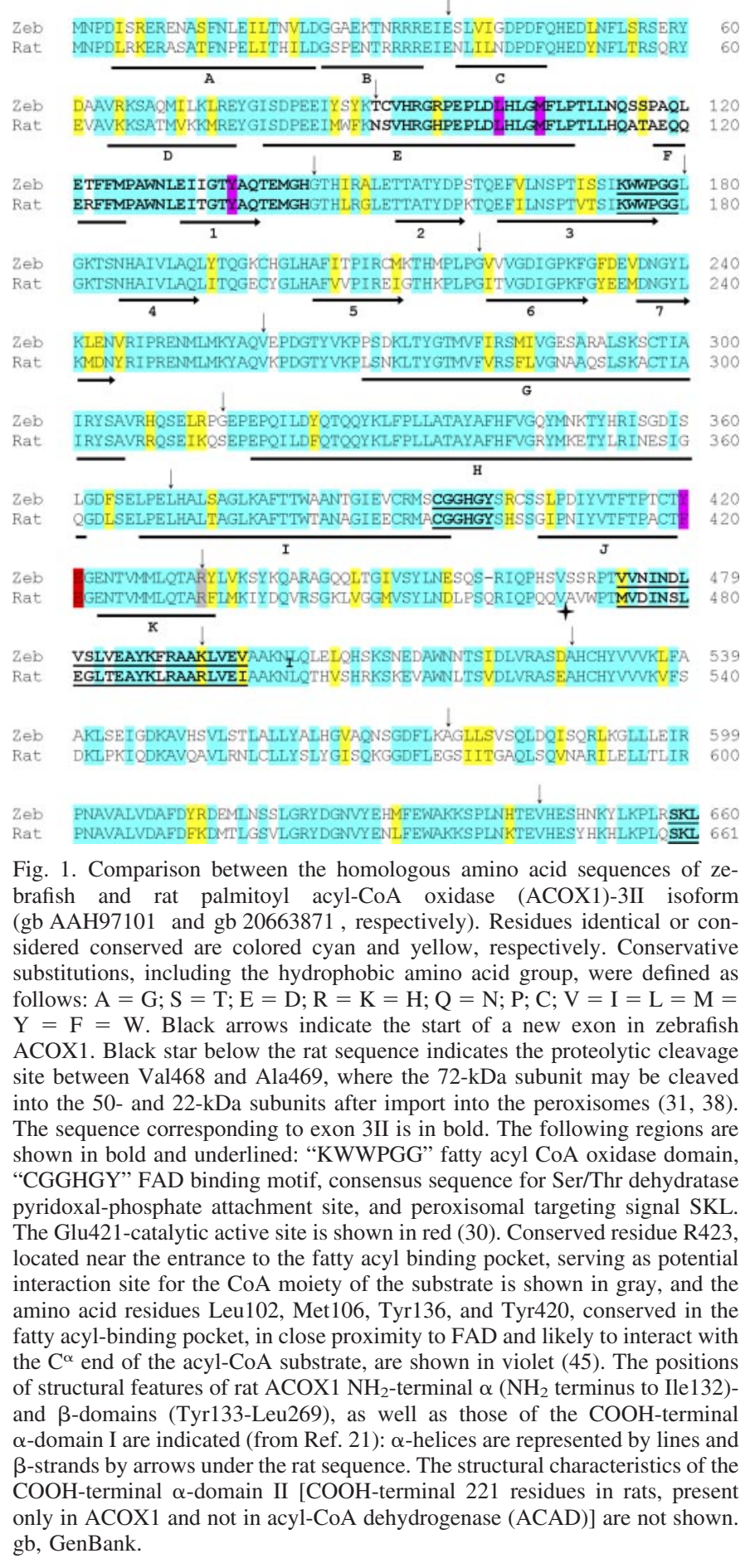

quences, which were also $44.4 \%$ identical at the amino acid sequence level. The two corresponding aligned deduced proteins showed a region of considerable difference across 43 amino acid residues, from position 90 to 133 (Fig. 2B).

The alignment of the amino acid sequences corresponding to the two alternative exon 3 splicing variants identified in different vertebrate species revealed that the last 10 amino acids (positions 134-143) in both variants were identical in all vertebrate species analyzed, except Met141, that was conservatively replaced by Leu141 in zebrafish, $P$. promelas (another teleost in the Cyprinidae family), rainbow trout, and Xenopus 3I isoforms (Fig. 2B). Other amino acids strictly conserved in both isoforms were: Met106, Phe107, Gln114, and Gln119 (with the exception of the human 3I isoform). Leu111 was also conserved, except for a conservative replacement by Ile111 in G. Gallus. In the initial part of exon 3, only Glu98, Leu100, and Leu102 were conserved (replaced conservatively by Asp98 or Val102 in the 3I isoform of Xenopus sp. or in zebrafish and P. promelas, respectively or by Val100 in the 3I isoform of humans and rats and by Phe 100 in the $3 \mathrm{I}$ isoform of chicken and $P$. promelas). Several other amino acids in the middle region of exon 3I and 3II were either conserved or conservatively replaced in mammals and teleosts, but diverged in Xenopus sp. and chicken. This is the case of Pro109 and Thr110, present in all species except Xenopus sp. and $G$. Gallus (for Pro109) and Xenopus sp. (for Thr110). Regarding the conserved residues within each isoform, there was a much higher degree of identity (68.5\%) for the 3II isoform, from lower to higher vertebrates, with a strict conservation of large regions of this isoform's sequence, in residues 92-93, 97-112, $114,119,124,126-130,132$, and 134-143. Moreover, if we disregard the T. nigroviridis and Fugu rubripes sequences, which are more divergent, identity increased to $76 \%$, due to the conservation of amino acids in positions 94, 95, 125, and 131. There was a much lower amino acid identity (only 26\%) between all the 3I isoform sequences analyzed for the different species, with strictly conserved residues in positions 101, 106, $107,114,123$, and 134-143 (except in residue 141, where a conservative replacement occurred in Xenopus sp., cyprinids, and rainbow trout). In Fig. $2 B$, some amino acid residues shown may be considered as markers of each isoform, as they are present in all sequences of that isoform but not in the alternative splice isoform. Only two amino acid residues (Gly101 and Trp123) can be considered markers for the 3I isoform, while a much larger number are characteristic of the 3II isoform: His93, Pro97, Asp101, Leu104, Gly105, Phe124, Trp128, and Asn129.

Comparison of vertebrate ACOX1 exon 3 isoform sequences with selected ACOX homologous sequences from other eukaryotic species revealed the presence of a mix of 3I and 3II isoform marker amino acids in the thale-cress (A. thaliana), ascomycetes (S. cerevisiae, Y. lipolytica), insects (T. castaneum, D. melanogaster), and urochordate (C. intestinalis) sequences (Supplemental Fig. S1; the online version of this article contains supplemental material).

Phylogenetic relationships of vertebrate ACOXs. The evolutionary relationship of vertebrate genes belonging to the ACOX protein family was evaluated after alignment of the conserved sequence motifs of ACOX proteins (Supplemental Fig. S2). The computer-derived phylogenetic tree (Fig. 3) grouped with confidence in separate clusters ACOX1, ACOX2, and ACOX3 sequences. Screening either expression (http:// www.ncbi.nlm.nih.gov and http://compbio.dfci.harvard.edu/tgi/) or genomic (http://www.ensembl.org/Danio_rerio/index.html) databases with cDNA or amino acid sequences for $X$. tropicalis ACOX2 (gb NM_001015986) did not reveal any evidence of the presence of ACOX2 or acox 2 transcripts in zebrafish or in other teleost species available. This absence was supported by the lack of sequence entries from the teleost lineage attached to TreeFam (http://www.treefam.org/) ACOX2 family (accession number: TF300672). In contrast, zebrafish ACOX3 and acox3 transcripts 


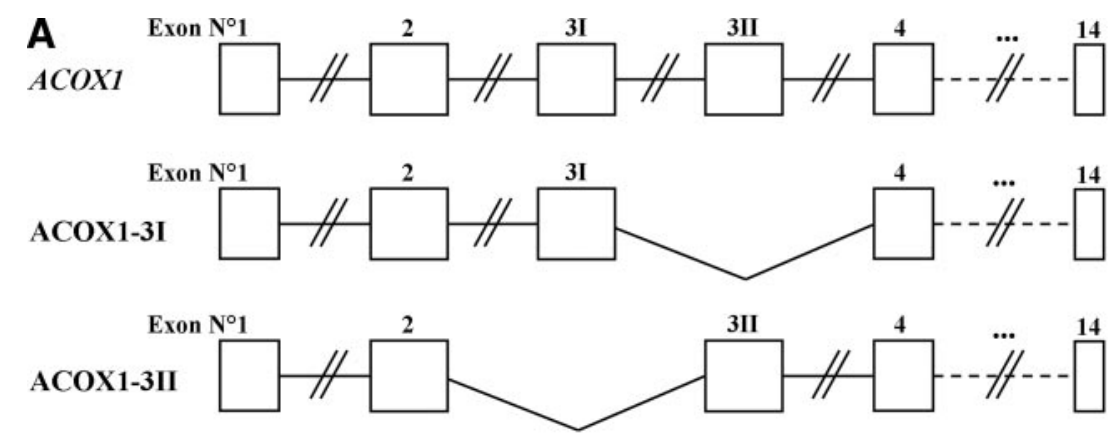

Fig. 2. Evolutionarily conserved acoxl alternative splicing variants in vertebrates. $A$ : exons and introns are represented by boxes and horizontal lines, respectively, and are not drawn to scale. The 2 alternative splice variants are depicted beneath the gene structure. $B$ : multiple alignment of the amino acid sequences corresponding to the two alternatively spliced exon 3 isoforms (3I and 3II) in different species. The species abbreviations refer to sequences from human (Hum), rat (Rat), chicken (Chi), Xenopus tropicalis (XeT), Xenopus laevis (XeL), zebrafish (Zeb), Pimephales promelas (Pim), Tetraodon nigroviridis (Tet), Takifugu rubripes (Fug), and rainbow trout (Tro). Amino acid sequence numbering starts from the initiator methionine. Missing data are indicated by dashes. Residues identical or considered conserved in both isoforms are colored cyan and yellow, respectively. Conservative substitutions were defined as in Fig. 1 legend. Amino acids that are considered markers of each isoform, i.e., present in all sequences of one isoform and absent in the alternative splice isoform, are colored in red. Sites of identical amino acids in all sequences of each isoform are indicated by an asterisk below the alignment. The position of structural features of rat ACOX1 (21) is indicated below the aligned sequences: helices $E$ and $F$ are represented by lines and $\beta$-strand 1 by an arrow.

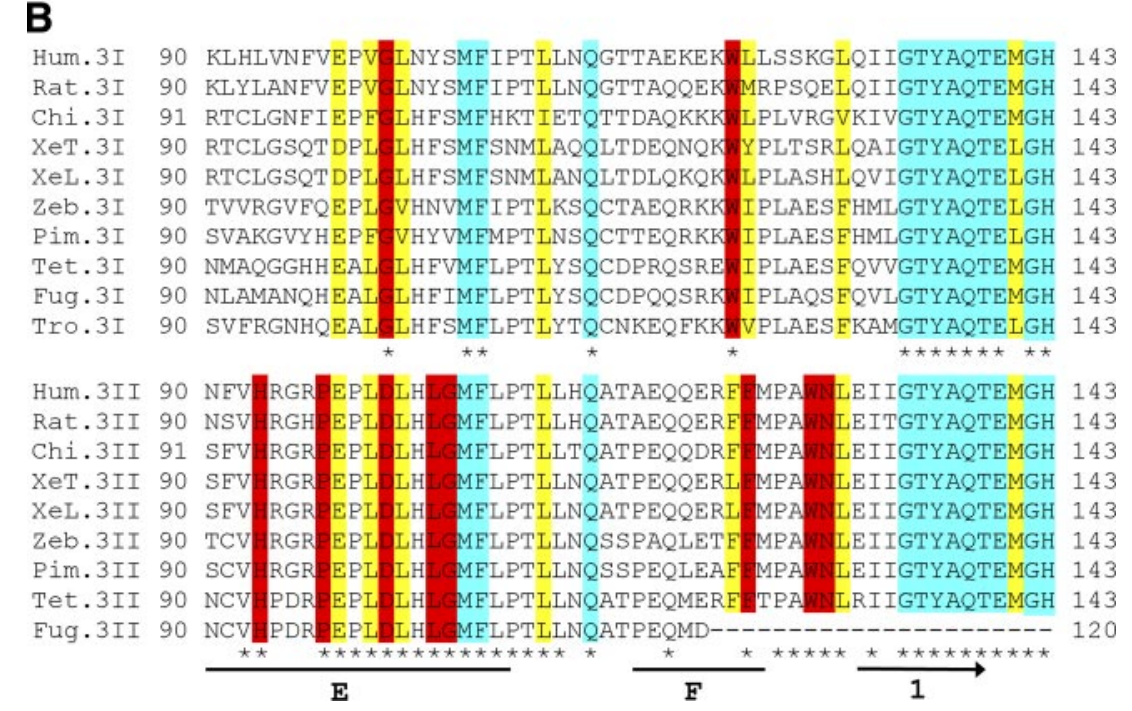

were present in expression databases (gb NM_213147) and attached to TreeFam ACOX3 family (accession number: TF314226). The cDNA sequence of zebrafish ACOX3 spans $3,798 \mathrm{bp}$, with an ORF from 73 to $2,151 \mathrm{bp}$, encoding a 692amino acid protein, and the gene (GeneID:406421 or ZFIN:ZDBGENE-040426-2163; UniGene Dr.18799) is positioned on chromosome 7. A region between position 117 and 632 of zebrafish ACOX1 aligns well with the region corresponding to amino acids $129-659$ of ACOX3, with an identity of 35\% (Supplemental Fig. S2). Comparison of vertebrate ACOX1 exon 3 isoform sequences with tetrapod ACOX2 or vertebrate ACOX3 amino acid se- quences revealed that the last 12 amino acids were highly conserved in ACOX2 sequences (Fig. S1 and data not shown).

Developmental expression pattern of acoxl in zebrafish. Whole mount in situ hybridizations with an antisense probe recognizing both splicing variants showed the presence of zebrafish acoxl transcripts in embryonic cells after gastrulation (data not shown). From 16 to $24 \mathrm{hpf}$, the hybridization signal still appeared to be uniformly and diffusely dispersed in the embryo, but a higher concentration started to be noticeable in the head region, including the developing eyes (Fig. 4A). Low-level labeling of some brain regions and structures ap-
Fig. 3. Phylogeny of vertebrate ACOX proteins. The neighbor-joining tree was based on the alignment of conserved sequences (Fig. S2) of ACOX proteins (475 aligned sites, Poisson-correction distance method, 5,000 bootstrap replicates). The numbers on the branches are bootstrap confidence levels. ACOX1, trihydroxycoprostanoyl-CoA oxidase (ACOX2), and pristanoyl-CoA oxidase (ACOX3) branches are separated with dotted lines. Accession numbers of sequences used are indicated in parentheses.

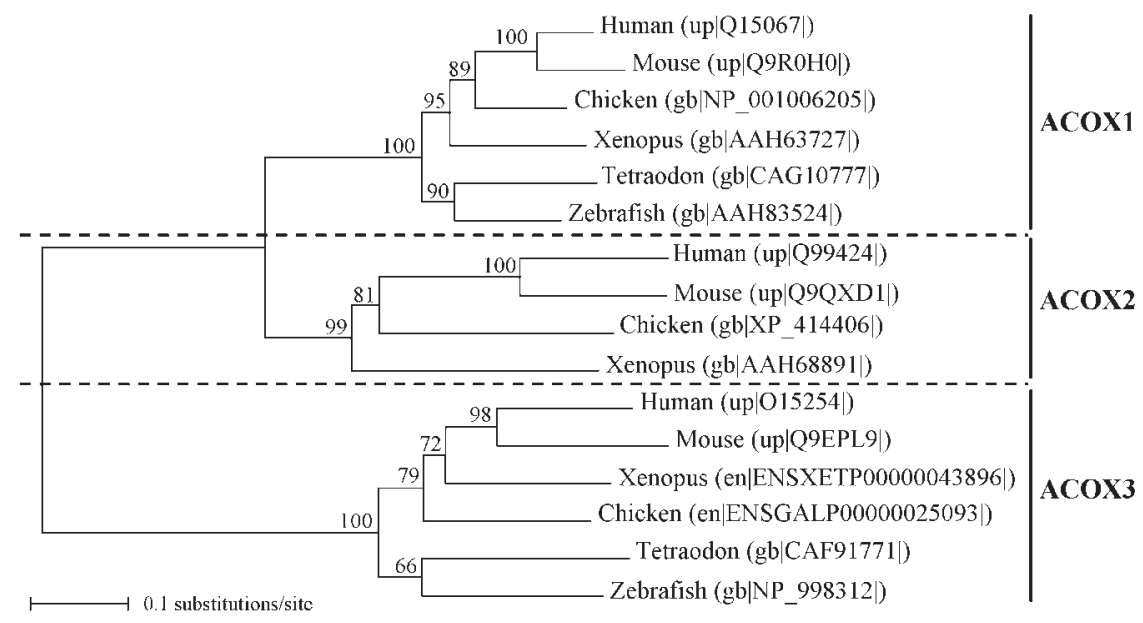




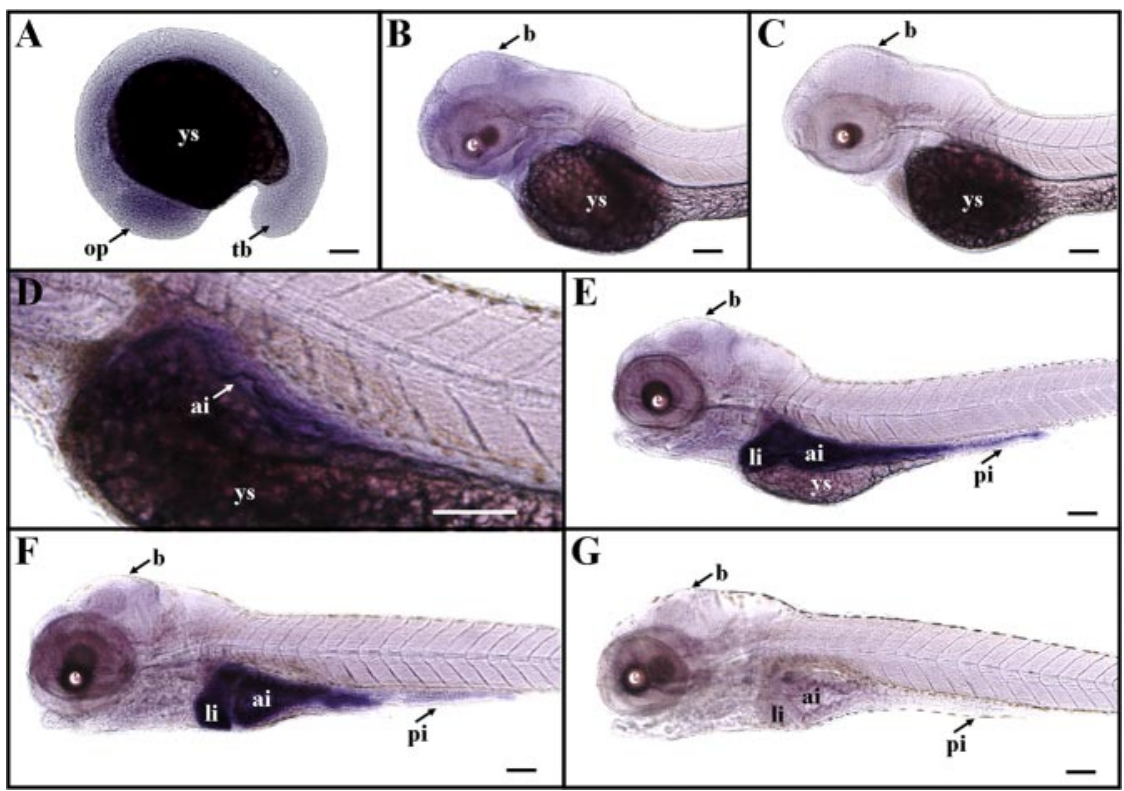

Fig. 4. Expression pattern of acoxl transcripts during zebrafish embryo and larva development. $A$ : 16 hours postfertilization (hpf). $B$ and $C$ : 2 days postfertilization (dpf). $D: 3$ dpf. $E: 4$ dpf. $F$ and $G: 5$ dpf. The animals were reared in water containing 0.15 mM 1-phenyl-2-thio-urea to prevent pigment formation and were hybridized with antisense $(A, B, D-F)$ or sense $(C, G)$ digoxigenin-labeled riboprobes. The hybridization signal is colored dark blue to purple. No staining signal was observed using the sense probe ( $C$ and $G$, as well as in the other stages, data not shown). The dark color in the yolk sac (ys) corresponds to an optical effect and is not a hybridization signal. At $16 \mathrm{hpf}$, the staining signal was diffusely dispersed throughout the whole embryo, but a higher concentration started to be visible in the head region, especially around the optic primordium (op). By $2 \mathrm{dpf}(B)$ and afterward ( 4 and $5 \mathrm{dpf}, E$ and $F$, respectively), the diffuse staining signal disappeared from the embryo body and faint labeling started to be visible in the brain (b). $D$ : higher magnification view of the anterior visceral area, at $3 \mathrm{dpf}$, where the gut tube is starting to form from the endodermic sheet, in an anterior-posterior direction. At 4 and 5 dpf $(E, F)$ the liver bud (li) and anterior intestine (ai) are intensely colored, while the posterior intestine (pi) also shows strong labeling, right through to the posterior end. ys, Yolk sac; op, optic primordium; tb, tail bud; e, eye; b, brain; li, liver; ai, anterior intestine; pi, posterior intestine. Scale bars $=100 \mu \mathrm{m}$.

peared by $2 \mathrm{dpf}$ (Fig. $4 B$ ) and was maintained until $5 \mathrm{dpf}$ (Fig. $4, E$ and $F$ ). From 3 dpf onward, the liver bud became more marked and showed an increasingly intense hybridization signal, clearly visible at 4 and 5 dpf (Fig. $4, E$ and $F$ ). By 3 dpf, the intestine had become functional, and a distinct acoxl transcript labeling was observed in the developing gut tube (Fig. $4 D$ ), which became very marked from 4 dpf onward (Fig. $4, E$ and $F$ ). This hybridization signal was particularly intense in the anterior region of the intestine, even though there were signs of acoxl transcripts right through to the end of the posterior intestine (Fig. 4, $E$ and $F$ ).

Differential expression of acoxl transcript splicing variants in adult zebrafish tissues. qPCR on zebrafish adult tissues indicated high relative levels of both acoxl transcript variants in the liver and anterior intestine and, to a lesser extent, in the brain (3I variant), heart, kidney, ovary, and testicle (data not shown). No significant differences were found between the normalized levels of both transcript variants in the liver and anterior intestine, although there was a trend toward higher levels of variant $3 \mathrm{I}$ in the intestine (1.5-fold) and variant $3 \mathrm{II}$ in the liver (1.5-fold) of fasting zebrafish. However, there was a very significant difference in the distribution of the two alternative splicing mRNAs in the brain of fasting zebrafish, with mRNA acoxl 3II variant levels sevenfold higher than those of the 3I variant, using both efl $\alpha$ and ppia 2 as normalizing genes (acoxl $3 \mathrm{II} /$ efl $\alpha$ vs. acoxl $3 \mathrm{I} /$ efl $\alpha=8.05 \pm 2.70$ vs. $1.11 \pm$ $0.43, P=0.002$, and acoxl $3 \mathrm{II} /$ ppia2 vs. acoxl $3 \mathrm{I} /$ ppia $2=$ $3.54 \pm 1.36$ vs. $0.51 \pm 0.25, P=0.002$ ). Therefore, the normalized level of the 3II transcript variant in brain was of the same order of magnitude as that in the intestine and liver of fasting zebrafish.

Nutritional regulation of acoxl expression in teleost fish. Whole mount in situ hybridizations on zebrafish larvae revealed the presence of acoxl transcripts in the liver and intestine, in both fed and fasting fish (Fig. 5). In the larval intestine, the labeling was particularly intense in the anterior part, but diffuse staining was noticeable through to the posterior end. By comparison with the fasting state, and regardless of the larval developmental stage, feeding resulted in a slight increase in the acoxl hybridization signal in the anterior intestine and, to a lesser extent, in the liver (Fig. 5, $B, C, E, F$, $H, I)$. No staining signal was detected in either fasting or fed larvae hybridized with the sense probe (Fig. 5, $A, D, G$ ).

The effect of feeding on the level of the two acoxl transcript variants resulting from alternative splicing was evaluated in zebrafish larvae and adult males by qPCR, using both efl $\alpha$ and ppia 2 as normalizing genes. Both reference genes yielded the same results, and thus Figs. 6 and 7 show results normalized only with ppia2. While transcript variant 3I tended to be present in higher concentrations in fed larvae at 5 and $15 \mathrm{dpf}$ than in fasting subjects, the differences were not statistically significant (Fig. 6). At 5 and $15 \mathrm{dpf}$, normalized levels of acox1 transcript variant $3 \mathrm{II}$ increased significantly, by 1.4 to 1.5 -fold $(P<0.05)$, in the whole larva after feeding (Fig. 6). This effect was not significant at $8 \mathrm{dpf}$. In adult males, the level of both acoxl transcript variants in the anterior intestine, but not in the liver, were significantly upregulated $(P<0.05)$ by feeding (Fig. 7). A significantly higher level of acoxl 3I and 3II 
Fed (sense)

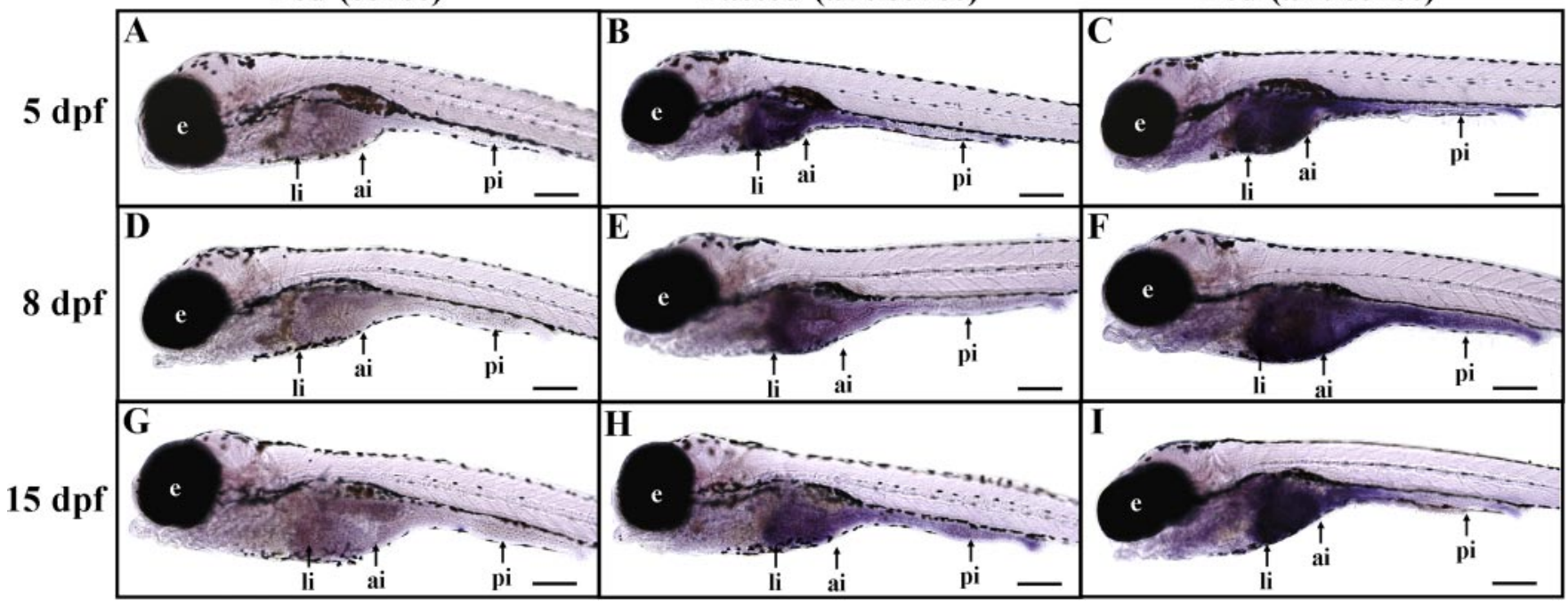

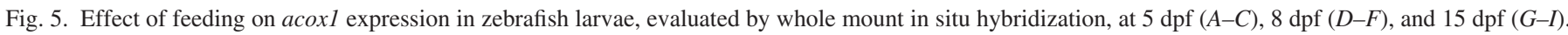

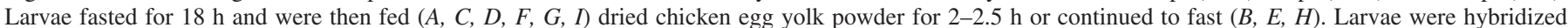

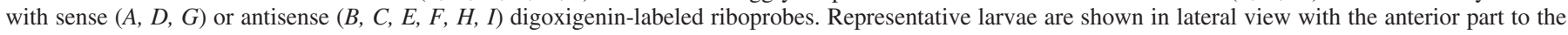

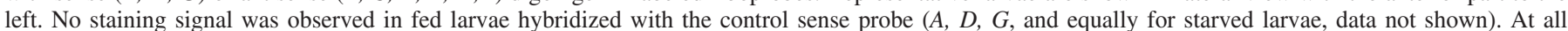

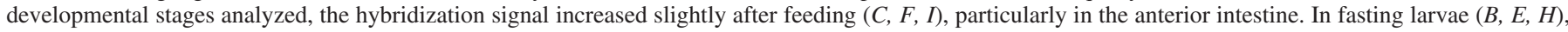

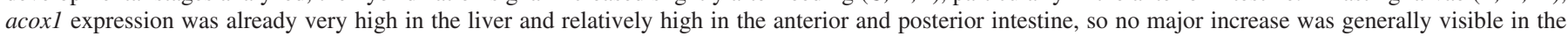
liver or posterior intestine after feeding. Scale bars $=200 \mu \mathrm{m}$.

transcript variants, 1.9- and 1.7-fold, respectively, was found in the anterior intestine of fed zebrafish adults, compared with the fasting group. The level of acoxl transcript variants in the liver increased between fed and fasting states, albeit nonsignificantly (1.6-1.7 or 1.3-1.4 times, depending on the normalizing gene).

qPCR analysis of juvenile trout, with primers potentially able to amplify both acoxl splicing transcript variants, using $\beta$-actin and efl $\alpha$ as reference genes, revealed a highly significant upregulation $(P<0.001$, fourfold, for both reference genes) of acoxl transcript levels after feeding (Fig. 8).

\section{DISCUSSION}

Evolutionary conservation of acoxl in vertebrates. The gene structure coding for ACOX1 is remarkably conserved in the vertebrate lineage. In all species where the full gene sequence is available, including humans (61), rats (41), chickens, $X$. tropicalis, and zebrafish (Ensembl genome database), the gene has 14 exons of similar size and 13 introns. Chu et al. (7) noticed that, in humans, $A C O X 1$ exon 14 has 48 bp instead of $51 \mathrm{bp}$, as in the orthologous rat gene and suggested either a single codon deletion event in the human gene or the insertion of a codon into rat Acoxl. Considering that, in the lower vertebrates analyzed, exon 14 also has $51 \mathrm{bp}$, the hypothesis of codon deletion in humans is more likely. In spite of this deletion, zebrafish and human ACOX1 have the same size, as a result of a codon insertion in exon 10 of zebrafish acoxl.

The zebrafish ACOX1 deduced protein shares several of the features commonly found in homologous yeast, plant, and mammal enzymes (Fig. 1) (16, 17, 39). These conservations include the "KWWPGG" fatty acyl-CoA oxidase domain (only fully conserved in a few plant ACOXs, such as Arabidopsis AtACX1 and barley) (17) and the "CGGHGY" FAD binding motif, as well as the Glu421 catalytic active site (30). In addition, like most other ACOXs, zebrafish ACOX1 has one SKL peroxisomal targeting signal at its carboxy-terminal end, which is conserved in many peroxisomal matrix proteins in animals, plants, and eukaryotic microorganisms (7, 27). Another characteristic feature of mammalian ACOX, in this case exclusive of ACOX1, is the presence of a proteolytic cleavage site between Val468 and Ala469, where the A subunit (72$\mathrm{kDa})$ may be cleaved into B $(50-\mathrm{kDa})$ and $\mathrm{C}(22-\mathrm{kDa})$ subunits in rats or $51-$ and $21-\mathrm{kDa}$ in humans, after import into the peroxisomes $(7,31,38)$. However, only Val467 is present in zebrafish ACOX1, while Ala469 has been replaced by Ser468 (difference in amino acid position due to the size dissimilarity of exon 10). As the surrounding amino acids are also divergent, it is unlikely that this cleavage site has been conserved in zebrafish, although experimental data are necessary to confirm this. Osumi et al. (41) noted that there was almost no homology between rat ACOX1 and yeast PXP4 and PXP5 around the site of proteolytic cleavage, which was also a region of comparatively low homology between zebrafish and rat ACOX1.

The consensus sequence for the Ser/Thr dehydratase pyridoxal-phosphate attachment site (38), found in all mammalian ACOX1, is also well conserved in the zebrafish sequence. Finally, the glutamate residue considered to be the catalytic base responsible for the $\alpha$-proton abstraction of the substrate in the ACAD and ACOX superfamily (65), is conserved in ACOX1 (Glu421 in both rat and zebrafish ACOX1 and Glu424 in Arabidopsis ACX1) $(34,45)$.

Phylogenetic relationships of vertebrate ACOXs and conserved alternative splicing transcript variants. Miyazawa et al. (31) compared the predicted amino acid sequence of rat ACOX1 with PXP4 and PXP5 in yeast ( $C$. tropicalis) and concluded that these genes must have derived from a common ancestor. Furthermore, Baumgart et al. (3) concluded that the mammalian $A C O X 3$ gene diverged early in evolution from a 


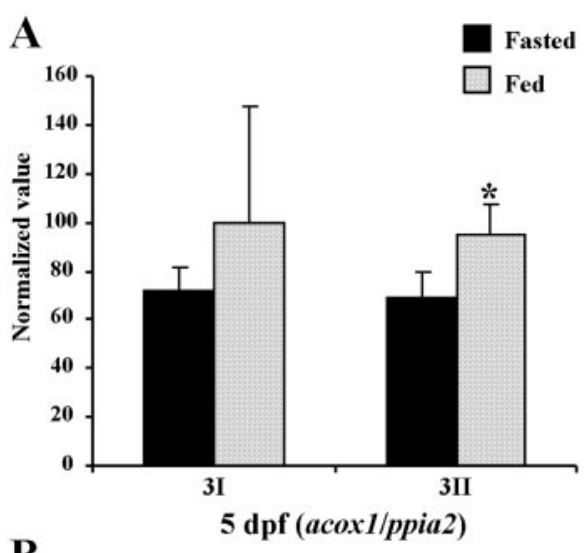

B
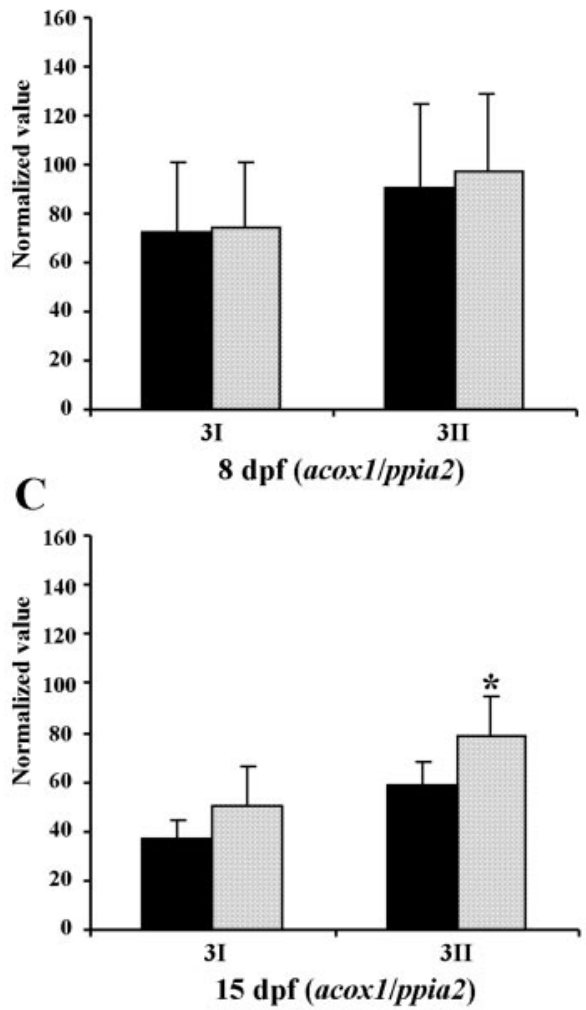

Fig. 6. Real-time quantitative RT-PCR (q-PCR) analysis of the expression of acox1 3I and 3II transcript variants produced by alternative splicing of exon 3, in whole zebrafish larvae homogenates, after a period of over $18 \mathrm{~h}$ fasting (fasted group) or after $18 \mathrm{~h}$ fasting followed by $2-2.5 \mathrm{~h}$ feeding (fed group), at 5,8 , and $15 \mathrm{dpf}$. At each age, 6 independent pools of 25 larvae (5 and $8 \mathrm{dpf}$ ) or 20 larvae (15 dpf) were used to quantify, in duplicate, acox1 3I and acoxl 3II transcript variants. Elongation factor $(e f l \alpha)$ and 2-peptidylprolyl isomerase A (ppia2) were also quantified and used as normalizing genes. The results shown are the number of copies of the acoxl variant divided by the number of copies of ppia 2 (normalization by efl $\alpha$ gave very similar results). *Significant differences $(P<0.05)$ between the fasted and fed groups, for the variant and age examined.

common ancestral gene, followed later by a divergence of the ACOX1 and ACOX2. In this study no evidence was found of acox2 in zebrafish, or in any other teleost species (Fig. 3), while zebrafish acox 3 was localized on chromosome 7 . The gene duplication event giving rise to $A C O X 1$ and $A C O X 2$ must have occurred after the split between the Sarcopterygii and the Actinopterygii, as no orthologous gene to ACOX2 could be identified in the current version releases of sequence databases in nontetrapod vertebrate species. The presence of ACOX2 in tetrapods may be linked to significant differences in bile acid-intermediate biochemical degradation pathways related to the bile acids produced $(6,15)$.

In rats, the observation that the two Acoxl transcripts arising from exon 3I or 3II skipping events had a homology of 55\% in nucleotide sequence suggested that the two sequences were produced by exon duplication $(31,41)$. An evolutionarily conserved alternative splicing of the corresponding acoxl primary transcript was identified in teleosts and tetrapods including mammals, giving rise, after exon skipping (Fig. $2 A$ ), to two splice variants, ACOX1-3I and ACOX1-3II. The homology between the two alternative exons in rats and humans is particularly high in the middle and $3^{\prime}$-end portions, suggesting that these portions are functionally significant $(31,61)$. On the other hand, the initial part of the sequence shows little similarity, possibly indicating that this region was not conserved because it was not important for enzyme function or, on the contrary, that the two isoforms have accumulated mutations in this part and thus evolved different functions (31). The alignment of the amino acid sequences corresponding to the two alternative exons 3 from different vertebrate species (Fig. $2 B$ ) revealed that this spatial difference in isoform homology is
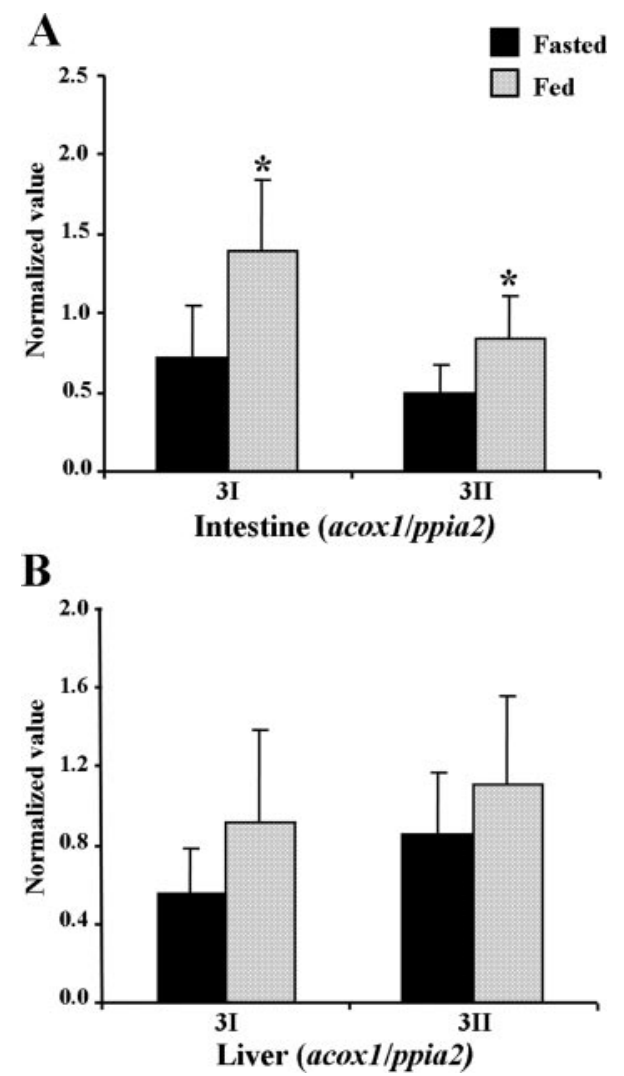

Fig. 7. q-PCR analysis of the expression of acox 13 I and 3II transcript variants produced by alternative splicing of exon 3 , in the dissected anterior intestine and liver of adult zebrafish, after a period of over $22 \mathrm{~h}$ fasting (fasted group) or after $22 \mathrm{~h}$ fasting followed by $2-2.5 \mathrm{~h}$ of feeding (fed group). Organs from 6 individuals were analyzed independently, in duplicate. The amount of efl $\alpha$ and ppia 2 transcripts was also quantified and used to express the results as the number of copies of each acoxl variant divided by the number of copies of each normalizing gene (not shown for efl $\alpha$ as it gave very similar results). *Significant differences $(P<0.05)$ between the fasted and fed groups, for the transcript variant and organ examined. 


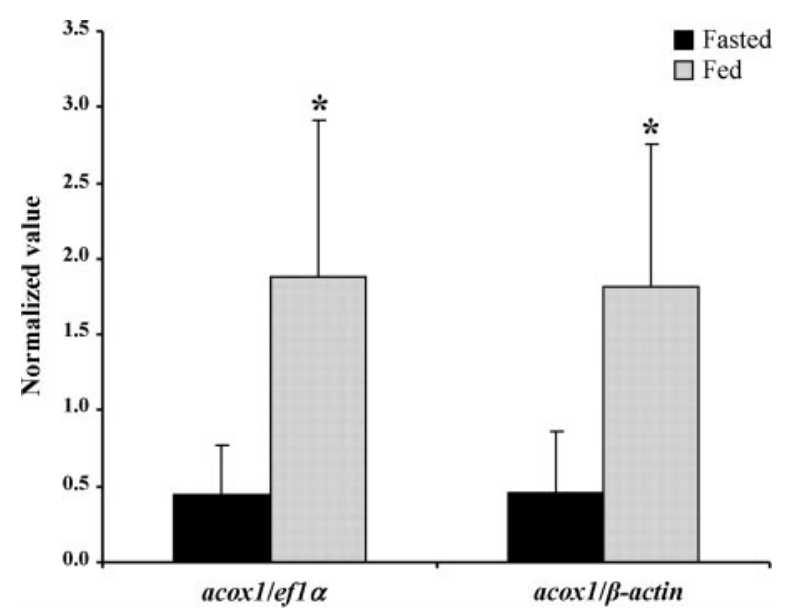

Fig. 8. q-PCR analysis of acoxl expression (both acoxl splicing transcript variants were quantified together), in the dissected anterior intestine of trout juveniles, after a period of 3 days' fasting (fasted group) or after 3 days' fasting followed by feeding and sampling $8 \mathrm{~h}$ afterwards (fed group). Organs from eight individuals were analyzed independently, in duplicate. The amount of efl $\alpha$ and $\beta$-actin transcripts was also quantified and used to express the results as the number of copies of acoxl transcripts divided by the number of copies of each normalizing gene. *Significant differences $(P<0.05)$ between the fasted and fed groups.

generalized, from teleosts to humans. These two exons may therefore have developed due to an intragenic tandem duplication event in a common ancestor of teleosts and tetrapods, i.e., before the split between the Sarcopterygii and the Actinopterygii. The presence of amino acid residues that may be considered as specific markers of ACOX1 3I or 3II isoforms in Osteichthyes species only (Fig. 2B) and a mix of 3I and 3II isoform marker amino acids in nonvertebrate sequences analyzed (Fig. S1) indicate a unique exon 3 duplication event that may have occurred at the basis of vertebrate evolution.

Developmental expression pattern and acoxl transcript tissue distribution. Rat Acox transcript level was highest in the liver, much lower in the kidneys, and was only present in trace amounts in other organs (4). Similarly, consistent with its role in lipid metabolism, Acoxl mRNA and protein expression in mice were most abundant in the liver, followed by the kidneys, brain, and adipose tissue (38). However, intestinal tissue was not analyzed.

Whole mount in situ hybridizations with a probe recognizing both splicing variants of zebrafish acoxl showed a strong hybridization signal in buds and full-grown livers (Fig. 4). Transcripts were detectable in the developing intestine from 3 dpf. A similar expression pattern was demonstrated in rat embryos, showing a remarkably intense ACOX immunolabeling of liver and, to a lesser extent, in the gut during development (35). In zebrafish larvae, on the other hand, localized acoxl transcript distribution in the intestine was also noted, with very intense labeling in the anterior intestine and a weaker hybridization signal in the posterior part. The high preponderance of acoxl transcripts in the liver and anterior intestine reveals a pivotal role of these tissues in peroxisomal fatty acid oxidation during embryonic and postembryonic development. It should be noted that the yolk syncytial layer does not express acoxl and may not be a site of fatty acid oxidation, although it plays an essential role in the transport of lipid nutrients to the developing embryo $(1,29,47)$.
A slight but consistent acoxl hybridization labeling in the developing nervous system (Fig. 4) and a strong differential expression of splice transcript variants in adult brains indicate that ACOX1 plays a role in zebrafish neuronal development and fatty acid homeostasis. In mammals, the brain is the richest source of VLCFA, and myelin, in particular, contains up to $20 \%$ fatty acids with over 18 carbon atoms (46). Compared with rat neural tissue, fish brain lipids have an even higher degree of unsaturation (57). Fish brain lipids are characterized by extremely high DHA levels, as well as other VLCFA, such as $20: 5 n-3$ (eicosapentaenoic acid), 20:4n-6, 22:4n-6, and, to a lesser extent, 24:0 and 24:1 $(33,57)$. As peroxisomal $\beta$-oxidation is the almost exclusive pathway of VLCFA degradation $(49,52)$, as well as being necessary for the retroconversion step in DHA biosynthesis $(48,53,55)$, it plays a key role in maintaining a steady-state biochemical composition in the brain. The immunolocalization of ACOX1 in the central nervous system of adult rats revealed a signal in the cytoplasm of neuronal and glial cells, with wide distribution throughout the entire brain (11). During mammalian embryonic development, an early and sustained appearance of peroxisomal enzymes, including ACOX, has been detected by immunohistochemistry in neuroblasts of several brain regions, in the spinal cord, as well as in cranial and spinal ganglia of rat (35) and in the basal ganglia, thalamus, and cerebellum of human embryos (18). During early developmental stages, when the formation of the central nervous system occurs, the peroxisomal $\beta$-oxidation system may be particularly active. The link between a number of peroxisomal disorders and brain dysmyelination and demyelination (49), together with a coordinated increase in the postnatal peroxisomal enzyme activity at the onset of myelination suggests that brain peroxisomes may play an important role in myelin assembly and turnover $(28,58)$. The inhibition of peroxisomal $\beta$-oxidation in young rats (from weaning to day 60 ) has been associated with a reduction in brain myelination (58). Therefore, ACOX1 is believed to be one of the enzymes responsible for the degradation of rat brain VLCFA during postnatal development (24), and its activity may be particularly important at specific moments in rodent brain development $(24,25)$. The findings of our study indicate that this may also be the case in fish. An accumulation of DHA has been observed in the phosphoglycerides of developing herring larva brains, which is consistent with the general pattern in birds and mammals (33). DHA has been demonstrated to be critical for fish larva brain development, particularly of the tectum opticum and cerebellum (19), and DHA dietary deficiencies are responsible for severe effects on swimming behavior and visual acuity $(5,19)$. Therefore, neural and visual structures must be in place before first feeding for larval fish to feed and develop normally.

Tissue distribution of zebrafish acoxl transcript splicing variants and hypothesized functional significance. A quantitative tissue-specific distribution of the two acoxl alternative splicing mRNAs was observed in zebrafish brains, where the level of the mRNA acoxl 3II variant was sevenfold higher than that of the 3I variant. This had been previously demonstrated in rats by Knoll et al. (24) but, in this case, through RT-PCR, only. Acoxl transcripts corresponding to the 3II variant were detected during rat brain development, while both variants were found in the liver. It is not clear whether the mRNA corresponding to the $3 \mathrm{I}$ variant is really absent from rat brains 
or these findings are due to a methodological limitation related to its detection at a much lower expression level.

Alternative splicing is one of the most important mechanisms for generating a large number of mRNA and protein isoforms from a small number of genes, leading to a huge increase in the complexity of the proteome (see Ref. 54 for an extensive review). Changes in the gene product caused by alternative splicing may be divided into three categories: introduction of stop codons, changes in the protein structure, and changes in the $5^{\prime}$ or $3^{\prime}$ untranslated region (54). In the case of the gene coding for ACOX1, alternative splicing occurs in the translated region of the mRNA and, therefore, affects the protein-coding region, thus falling into the second category. Changes in the primary protein structure, caused by alternative splicing, have been implicated in changes in almost all aspects of protein function, such as binding properties, intracellular localization, enzymatic activity, and protein stability. It has also been implicated in posttranslational modifications, with effects ranging from a complete loss of function or acquisition of a new function to only very subtle changes (54). In the human transcriptome, although alternative splicing can be found in all tissues, the majority of the tissue-specific variants are found in the brain $(20,63)$. Knowing whether a gene is alternatively spliced in a tissue-specific manner and the location of the tissue-specific isoform may give some clues as to its possible functional role.

The physiological significance of the occurrence of two highly similar isoforms of ACOX1 is not completely clear, and the much greater divergence of the 3I isoform, compared with the 3II splicing isoform, is even less explicable. However, the conservation of the two alternatively spliced exons in all vertebrates analyzed suggests that this exon-skipping event is of real functional importance. Setoyama et al. (51) and Tamaoki et al. (56), based on the alignment of ACOX1 and medium-chain ACAD (30), hypothesized that alternative splicing may affect the enzyme's substrate specificity. They confirmed by X-ray crystallography of ACAD that the amino acid stretch corresponding to the third exon of ACOX1 was located in the helix that in ACAD constitutes the binding site and interacts specifically with substrates (22). This theory gained further support from the fact that the two ACOX1 isoforms were shown to exhibit different substrate specificities in rats, where ACOX1-3I activity was optimum at shorter chain length, compared with ACOX1-3II (51). Furthermore, in the study by Tamaoki et al. (56), differences in the spectroscopic properties of the two isoforms of ACOX1 confirmed the differences in substrate specificity revealed by the enzymatic studies. More recently, the three-dimensional structure of rat ACOX1, corresponding to the 3II isoform (34), as well as of a plant ACOX1, A. thaliana ACX1 (45), were characterized. The A. thaliana ACX1 overall folding and topology was similar to that of rat ACOX1-3II, although there are a number of structural differences. A comparison of the structure of plant and rat ACOXs, together with those of ACADs, provided insight into the structural basis for the variety in substrate preferences displayed by these enzymes (45). Pedersen and Henriksen (45) verified that the position of the substrate-binding pocket was similar in ACX1, rat ACOX1-3II, and ACAD:substrate complexes. Some conserved residues, such as ACX1 Arg436, are located near the entrance to the fatty acyl-binding pocket and act as a potential interaction site for the CoA moiety of the substrate. In the present study, the same residue, corresponding to $\operatorname{Arg} 433$, was found to be conserved in zebrafish ACOX1. Amino acid residues corresponding to those conserved in the fatty acyl-binding pocket of ACXs, found in close proximity to $\mathrm{FAD}$, and likely to interact with the $\mathrm{C}^{\alpha}$ end of the acyl-CoA substrate, were also found in zebrafish, i.e., Tyr136, Leu102, (ACOX1-3II) or Val102 (ACOX1-3I), Met106, and Tyr420. In different ACADs, changes in substrate specificities were caused by insertions in helix E (21). In fact, the structural alignment of different ACADs revealed that the homologous strands and helices had the same number of residues, with the exception of helix $\mathrm{E}$ where, for instance, the insertion of one amino acid residue caused a structural shift resulting in a shallower binding cavity in short-chain ACAD (2). Furthermore, Pedersen and Henriksen (45) noted that this helix and its adjacent residues constituted one of the least-conserved areas in ACX and ACAD structures and suggested that one of the characteristics of the ACAD superfamily may be the definition of substrate specificity by introducing modifications in this area. Interestingly, the start of exon 3, which shows little similarity between the two splicing isoforms is, in fact, localized in helix E (Fig. 2B). Additionally, within the 3II isoform, the "PEPLDLHLG" residues, conserved in all sequences of exon 3II from zebrafish to humans, are located in this helix, while one of the two marker amino acid residues of this 3I isoform is also located in helix E. On the contrary, part of the $\mathrm{COOH}$-terminal region, identical in both splicing isoforms of exon 3 in all the animals examined, is positioned in strand 1, part of the $\mathrm{NH}_{2}$-terminal $\beta$-sheet domain.

The difference in substrate specificity between the two ACOX1 isoforms, with ACOX1-3II being more active toward longer acyl chains, may explain its preponderance in the brain, which has particularly high VLCFA levels, as mentioned above. The higher degree of conservation of this isoform between species indicates that its role in the fatty acid catabolism may have been better preserved during evolution than that of splicing variant 3I. Indeed, if the 3II isoform has greater specificity for VLCFA, such as those found in neural tissue and structural membranes, that have a much more stable composition across the vertebrates, this would have limited its divergence. Conversely, it may be hypothesized that the 3I isoform may have diverged more strongly through evolution to adapt the organisms to their dietary and compositional specificities. In this respect, it was interesting to note a trend toward slightly higher levels of the $3 \mathrm{I}$ isoform in the intestine, i.e., the site of entry and primary metabolism of nutrients into the body, while the opposite was observed in the liver. Similarly, in koala liver, the enzymatic activity of the cDNA-expressed ACOX1-3II isoform was found to be considerably higher than that of the 3I isoform (37). However, this remains speculative and further studies are necessary to clarify the specific physiological role of each ACOX1 isoform.

Regulation of acoxl expression in zebrafish and trout by feeding. The nutritional regulation of ACOX was examined in adult rats, where an increase in dietary lipid level resulted in an increase in specific enzymatic $\beta$-oxidation activity in the liver (36). The same variation in Acoxl mRNA levels was observed in the immature liver and heart of developing rats weaned on diets with different lipid levels (43). Acoxl mRNA levels in the renal cortex of rat pups weaned on a high fat diet were also upregulated (42). In young pigs, food deprivation resulted in 
decreased hepatic peroxisomal $\beta$-oxidation at $24 \mathrm{~h}$ but had no effect either on kidney or heart peroxisomal $\beta$-oxidation (64). There is, thus, strong evidence of nutritional regulation of Acoxl expression, which appears to be widespread in all eukaryotes. Even in S. cerevisiae yeast, expression of the POXI gene was regulated at transcription level, with an increase of $>25$-fold induced by adding oleic acid to the medium (9).

In this work, nutritional regulation of acoxl transcript levels was examined in teleost fish, in response to feeding or fasting rather than to a change in dietary composition. In trout, the qPCR enabled amplification of both acoxl splicing transcripts, but, in zebrafish, the two acoxl transcript variants resulting from alternative splicing were quantified separately. In both species, a significant pretranslational upregulation of acoxl expression was observed in the adult and juvenile anterior intestine after feeding (1.9- and 1.7-fold for acoxl 3I and 3II transcript variants, respectively, in zebrafish, and 4-fold in trout). Conversely, no significant differences in either of the acoxl mRNA transcripts were observed in adult zebrafish liver, in spite of a general trend toward higher levels in fed animals (1.6-1.7 or 1.3-1.4 times higher, for 3I and 3II transcript variants, respectively). Whole mount in situ hybridization revealed that the acoxl transcript staining signal was more intense in zebrafish fed larvae than in the fasting group, especially in the anterior intestine. However, considerable levels of both acoxl transcripts (as the probe was not variant specific) were also present in the posterior intestine and, particularly, in the liver of fasting larvae, resulting in a relatively slight difference between the two experimental groups. qPCR at larval stages indicated a significant pretranslational upregulation of acoxl expression of only transcript 3II variant, induced by feeding at 5 and $15 \mathrm{dpf}$, but not at $8 \mathrm{dpf}$, even if the normalized expression ratios between the fed and starved larvae were similar for both splicing variants. The difference in results obtained with the two techniques used may be due to technical limitations and practical differences, which were accentuated by small differences in expression levels, i.e., a maximum of 1.5-fold between fed and fasted larvae, measured by qPCR. While whole mount in situ hybridization revealed the precise localization of the target transcript, q-PCR, using whole larvae homogenates, resulted in considerable dilution of the target "signal" to be amplified. It could be argued that this dilution should have even more impact at $15 \mathrm{dpf}$, when significant differences were found for the acoxl transcript 3II variant, but there may be other confounding factors, such as differences in transcript levels at different stages of nutritional development and individual variation between the samples. All together, these results point to a significant pretranslational upregulation of zebrafish and rainbow trout acoxl expression in the anterior intestine after feeding.

In conclusion, the evolutionary conservation of the structure of the gene coding for ACOX1, the alternative splicing and differential tissue expression, particularly in the brain, together with the significant nutritional pretranslational upregulation of acoxl expression in fish larvae, juveniles, and adults, indicate the fundamental conserved role of ACOX1 isoforms in the vertebrate fatty acid metabolism. Some hypotheses are discussed concerning the possible specific physiological roles of the two highly similar isoforms, but these need further experimental evidence.

\section{ACKNOWLEDGMENTS}

A. Knoll-Gellida and P. J. Babin designed research; S. Morais, A. KnollGellida, M. André, and C. Barthe performed research; S. Morais, A. KnollGellida, and. P. J. Babin analyzed data; and S. Morais and P. J. Babin wrote the paper.

\section{GRANTS}

This work was supported in part by the French Ministry of Research and Education and by the AGENAE program (P. J. Babin). S. Morais was supported by a postdoctoral fellowship from the French government.

\section{REFERENCES}

1. Babin PJ, Thisse C, Durliat M, André M, Akimenko MA, Thisse B. Both apolipoprotein E and A-I genes are present in a nonmammalian vertebrate and are highly expressed during embryonic development. Proc Natl Acad Sci USA 94: 8622-8627, 1997.

2. Battaile KP, Molin-Case J, Paschke R, Wang M, Bennet D, Vockley J, Kim JJP. Crystal structure of rat short chain acyl-CoA dehydrogenase complexed with acetoacetyl-CoA. J Biol Chem 277: 12200-12207, 2002.

3. Baumgart E, Vanhooren JCT, Fransen M, Marynen P, Puype M, Vandekerckhove J, Leunissen JAM, Fahimi HD, Mannaerts GP, Van Veldhoven PP. Molecular characterization of the human peroxisomal branched-chain acyl-CoA oxidase: cDNA cloning, chromosomal assignment, tissue distribution, and evidence for the absence of the protein in Zellweger syndrome. Proc Natl Acad Sci USA 93: 13748-13753, 1996.

4. Bell DR, Bars RG, Elcombe CR. Differential tissue-specific expression and induction of cytochrome P450IVA1 and acyl-CoA oxidase. Eur J Biochem 206: 979-986, 1992.

5. Bell MV, Batty RS, Dick JR, Fretwell K, Navarro JC, Sargent JR. Dietary deficiency of docosahexaenoic acid impairs vision at low light intensities in juvenile herring (Clupea harengus L.). Lipids 30: 443-449, 1995.

6. Casteels M, Schepers L, Van Veldhoven PP, Eyssen HJ, Mannaerts GP. Separate peroxisomal oxidases for fatty acyl-CoAs and trihydroxycoprostanoyl-CoA in human liver. J Lipid Res 31: 1865-1872, 1990.

7. Chu R, Varanasi U, Chu S, Lin Y, Usuda N, Rao MS, Reddy JK. Overexpression and characterization of the human peroxisomal acyl-CoA oxidase in insect cells. J Biol Chem 270: 4908-4915, 1995.

8. Cotto E, André M, Forgue J, Fleury HJ, Babin PJ. Molecular characterization, phylogenetic relationships, and developmental expression patterns of prios genes in zebrafish (Danio rerio). FEBS J 272: 500-513, 2005.

9. Dmochowska A, Dignard D, Maleszka R, Thomas DY. Structure and transcriptional control of the Saccharomyces cerevisiae POX1 gene encoding acyl-coenzyme A oxidase. Gene 88: 247-252, 1990.

10. Fan CY, Pan J, Chu R, Lee D, Kluckman KD, Usuda N, Singh I, Yeldandi AV, Rao MS, Maeda N, Reddy JK. Hepatocellular and hepatic peroxisomal alterations in mice with a disrupted peroxisomal fatty acylcoenzyme A oxidase gene. J Biol Chem 271: 24698-24710, 1996.

11. Farioli-Vecchioli S, Moreno S, Ceru MP. Immunocytochemical localization of acyl-CoA in the rat central nervous system. J Neurocytol 30: 21-33, 2001.

12. Feroze-Merzoug F, Berquin IM, Dey J, Chen YG. Peptidylprolyl isomerase A (PPIA) as a preferred internal control over GAPDH and $\beta$-actin in quantitative RNA analysis. Biotechniques 32: 776-782, 2002.

13. Fournier B, Saudubray JM, Benichou B, Lyonnet S, Munnich A, Clevers H, Poll BT. Large deletion of the peroxisomal acyl-CoA oxidase gene in pseudoneonatal adrenoleukodystrophy. J Clin Invest 94: 526-531, 1994.

14. Gao D, Li Z, Murphy T, Sauerbier W. Structure and transcription of the gene for translation elongation factor 1 subunit alpha of zebrafish (Danio rerio). Biochim Biophys Acta 1350: 1-5, 1997.

15. Haslewood GAD. Bile salt evolution. J Lipid Res 8: 535-550, 1967.

16. Hayashi H, Bellis LD, Yamaguchi K, Kato A, Hayashi M, Nishimura M. Molecular characterization of a glyoxysomal long chain acyl-CoA oxidase that is synthesized as a precursor of higher molecular mass in pumpkin. J Biol Chem 273: 8301-8307, 1998.

17. Hooks MA, Kellas F, Graham IA. Long-chain acyl-CoA oxidases of Arabidopsis. Plant J 20: 1-13, 1999.

18. Houdou S, Takashima S, Suzuki Y. Immunohistochemical expression of peroxisomal enzymes in developing human brain. Mol Chem Neuropathol 19: 235-248, 1993. 
19. Ishizaki Y, Masuda R, Uematsu K, Shimizu K, Arimoto M, Takeuchi T. The effect of dietary docosahexaenoic acid on schooling and brain development in larval yellowtail. J Fish Biol 58: 1691-1703, 2001.

20. Kan Z, Garrett-Engele PW, Johnson JM, Castle JC. Evolutionarily conserved and diverged alternative splicing events show different expression and functional profiles. Nucleic Acids Res 33: 5659-5666, 2005.

21. Kim JJP, Miura R. Acyl-CoA dehydrogenases and acyl CoA oxidases. Structural basis for mechanistic similarities and differences. Eur J Biochem 271: 483-493, 2004.

22. Kim JJP, Wang M, Paschke R. Crystal structures of medium-chain acyl-CoA dehydrogenase from pig liver mitochondria with and without substrate. Proc Natl Acad Sci USA 90: 7523-7527, 1993.

23. Kimmel CB, Ballard WW, Kimmel SR, Ullmann B, Schilling TF. Stages of embryonic development of the zebrafish. Dev Dyn 203: 253 310, 1995.

24. Knoll A, Sargueil F, Salles J, Cassagne C, Garbay B. Gene expression of peroxisomal $\beta$-oxidation enzymes in rat brain. Mol Brain Res 74: 217-220, 1999.

25. Knoll A, Salles J, Sargueil F, Cassagne C, Garbay B. Peroxisomal beta-oxidation enzyme gene expression in the developing mouse brain. Neurosci Lett 285: 201-204, 2000.

26. Kumar S, Tamura K, Nei M. MEGA3: integrated software for molecular evolutionary genetics analysis and sequence alignment. Brief Bioinform 5: 150-163, 2004.

27. Kunau WH, Dommes V, Schulz H. $\beta$-oxidation of fatty acids in mitochondria, peroxisomes, and bacteria: a century of continued progress. Prog Lipid Res 34: 267-342, 1995.

28. Lazo O, Singh AK, Singh I. Postnatal development and isolation of peroxisomes from brain. J Neurochem 56: 1343-1353, 1991.

29. Marza E, Barthe C, Andre M, Villeneuve L, Helou C, Babin PJ. Developmental expression and nutritional regulation of a zebrafish gene homologous to mammalian microsomal triglyceride transfer protein large subunit. Dev Dyn 232: 506-518, 2005.

30. Matsubara Y, Indo Y, Naito E, Ozasa H, Glassberg R, Vockley J, Ikeda Y, Kraus J, Tanaka K. Molecular cloning and nucleotide sequence of cDNAs encoding the precursors of rat long chain acyl-coenzyme A, short chain acyl-coenzyme A, and isovaleryl-coenzyme A dehydrogenases. J Biol Chem 264: 16321-16331, 1989.

31. Miyazawa S, Hayashi H, Hijikata M, Ishii N, Furuta S, Kagamiyama H, Osumi T, Hashimoto T. Complete nucleotide sequence of cDNA and predicted amino acid sequence of rat acyl-CoA oxidase. J Biol Chem 262: 8131-8137, 1987.

32. Moore SA, Hurt E, Yoder E, Sprecher H, Spector AA. Docosahexaenoic acid synthesis in human skin fibroblasts involves peroxisomal retroconversion of tetracosahexaenoic acid. J Lipid Res 36: 2433-2443, 1995.

33. Mourente G, Tocher DR. Lipid class and fatty acid composition of brain lipids from Atlantic herring (Clupea harengus) at different stages of development. Mar Biol (Berl) 112: 553-558, 1992.

34. Nakajima Y, Miyahara I, Hirotsu K, Nishina Y, Shiga K, Setoyama C, Tamaoki H, Miura R. Three-dimensional structure of the flavoenzyme acyl CoA oxidase-II from rat liver, the peroxisomal counterpart of mitochondrial acyl-CoA dehydrogenase. J Biochem (Tokyo) 131: 365-374, 2002.

35. Nardacci R, Falciatori I, Moreno S, Stefanini S. Immunohistochemical localization of peroxisomal enzymes during rat embryonic development. J Histochem Cytochem 52: 423-436, 2004.

36. Neat CE, Thomassen MS, Osmundsen H. Induction of peroxisomal $\beta$-oxidation in rat liver by high-fat diets. Biochem $J$ 186: 369-371, 1980.

37. Ngo SNT, McKinnon RA, Stupans I. Identification and cloning of two forms of liver peroxisomal fatty acyl CoA oxidase from the koala (Phascolarctos cinereus). Gene 309: 91-99, 2003.

38. Nöhammer C, El-Shabrawi Y, Schauer S, Hiden M, Berger J, ForssPetter S, Winter E, Eferl R, Zechner R, Hoefler G. cDNA cloning and analysis of tissue-specific expression of mouse peroxisomal straight-chain acyl-coA oxidase. Eur J Biochem 267: 1254-1260, 2000.

39. Okazaki K, Takechi T, Kambara N, Fukui S, Kubota I, Kamiryo T. Two acyl-coenzyme A oxidases in peroxisomes of the yeast Candida tropicalis: primary structures deduced from the genomic DNA sequence. Proc Natl Acad Sci USA 83: 1232-1236, 1986.

40. Okazaki K, Tan H, Fukui S, Kubota I, Kamiryo T. Peroxisomal acyl-coenzyme A oxidase multigene family of the yeast Candida tropi- calis; nucleotide sequence of a third gene and its protein product. Gene 58: 37-44, 1987.

41. Osumi T, Ishii N, Miyazawa S, Hashimoto T. Isolation and structural characterization of the rat acyl-CoA oxidase gene. J Biol Chem 262: $8138-8143,1987$.

42. Ouali F, Djouadi F, Merlet-Bénichou C, Bastin J. Dietary lipids regulate $\beta$-oxidation enzyme gene expression in the developing rat kidney. Am J Physiol Renal Physiol 275: F777-F784, 1998.

43. Ouali F, Djouadi F, Merlet-Bénichou C, Riveau B, Bastin J. Regulation of fatty acid transport protein and mitochondrial and peroxisomal $\beta$-oxidation gene expression by fatty acids in developing rats. Pediatr Res 48: 691-696, 2000.

44. Panserat S, Perrin A, Kaushik S. High dietary lipids induce liver glucose-6-phosphatase expression in rainbow trout (Oncorhynchus mykiss). J Nutr 132: 137-141, 2002.

45. Pedersen L, Henriksen A. Acyl-CoA oxidase from Arabidopsis thaliana. Structure of a key enzyme in plant lipid metabolism. J Mol Biol 345: 487-500, 2005.

46. Polous A. Very long chain fatty acids in higher animals: a review. Lipids 30: 1-14, 1995.

47. Poupard G, André M, Durliat M, Ballagny C, Bœuf G, Babin PJ. Apolipoprotein E gene expression correlates with endogenous lipid nutrition and yolk syncytial layer lipoprotein synthesis during fish development. Cell Tissue Res 300: 251-261, 2000.

48. Qiu X. Biosynthesis of docosahexaenoic acid (DHA, 22:6-4, 7,10,13,16,19): two distinct pathways. Prostaglandins Leukot Essent Fatty Acids 68: 181-186, 2003.

49. Reddy JK, Hashimoto T. Peroxisomal $\beta$-oxidation and peroxisome proliferator-activated receptor $\alpha$ : an adaptative metabolic system. Annu Rev Nutr 21: 193-230, 2001.

50. Schepers L, Van Veldhoven PP, Casteels M, Eyssen HJ, Mannaerts GP. Presence of three acyl-CoA oxidases in rat liver peroxisomes. An inducible fatty acyl-CoA oxidase, a noninducible fatty acyl-CoA oxidase, and a noninducible trihydroxycoprostanoyl-CoA oxidase. J Biol Chem 265: 5242-5246, 1990.

51. Setoyama C, Tamaoki H, Nishina Y, Shiga K, Miura R. Functional expression of two forms of rat acyl-CoA oxidase and their substrate specificities. Biochem Biophys Res Commun 217: 482-487, 1995.

52. Singh I, Moser AE, Goldfischer S, Moser HW. Lignoceric acid is oxidized in the peroxisome: implications for the Zellweger cerebrohepato-renal syndrome and adrenoleukodystrophy. Proc Natl Acad Sci USA 81: 4203-4207, 1984.

53. Sprecher H. The roles of anabolic and catabolic reactions in the synthesis and recycling of polyunsaturated fatty acids. Prostaglandins Leukot Essent Fatty Acids 67: 79-83, 2002.

54. Stamm S, Ben-Ari S, Rafalska I, Tang Y, Zhang Z, Toiber D, Thanaraj TA, Soreq H. Function of alternative splicing. Gene 344: 1-20, 2005.

55. Su HM, Moser AB, Moser HW, Watkins PA. Peroxisomal straightchain acyl-CoA oxidase and D-bifunctional protein are essential for the retroconversion step in docosahexaenoic acid synthesis. J Biol Chem 276: 38115-38120, 2001.

56. Tamaoki H, Setoyama C, Miura R, Hazekawa I, Nishina Y, Shiga K. Spectroscopic studies of rat liver acyl-CoA oxidase with reference to recognition and activation of substrate. J Biochem (Tokyo) 121: 11391146, 1997.

57. Tocher DR, Harvie DG. Fatty acid compositions of the major phosphoglycerides from fish neural tissues; (n-3) and (n-6) polyunsaturated fatty acids in rainbow trout (Salmo gairdneri) and cod (Gadus morhua) brains and retinas. Fish Physiol Biochem 5: 229-239, 1988.

58. Van den Branden C, Leeman J, Dacremont G, Collumbien R, Roels F. Experimental inhibition of peroxisomal $\beta$-oxidation in rats: influence on brain myelination. Glia 3: 458-463, 1990.

59. Vanhooren JC, Marynen P, Mannaerts GP, Van Veldhoven PP. Evidence for the existence of a pristanoyl-CoA oxidase gene in man. Biochem J 325: 593-599, 1997.

60. Vanhove GF, Van Veldhoven PP, Fransen M, Denis S, Eyssen HJ, Wanders RJA, Mannaerts GP. The CoA esters of 2-methyl-branched chain fatty acids and of the bile acid intermediates di- and trihydroxycoprostanic acids are oxidized by one single peroxisomal branched chain acyl-CoA oxidase in human liver and kidney. J Biol Chem 268: 1033510344, 1993.

61. Varanasi U, Chu R, Chu S, Espinosa R, LeBeau MM, Reddy JK. Isolation of the human peroxisomal acyl-CoA oxidase gene: organization, 
promoter analysis, and chromosomal localization. Proc Natl Acad Sci USA 91: 3107-3111, 1994

62. Wanders RJ. Peroxisomes, lipid metabolism, and peroxisomal disorders. Mol Genet Metab 83:16-27, 2004.

63. Xu Q, Modrek B, Lee C. Genome-wide detection of tissue-specific alternative splicing in the human transcriptome. Nucleic Acids Res 30: 3754-3766, 2002.
64. Yu XX, Drackley JK, Odle J. Rates of mitochondrial and peroxisomal $\beta$-oxidation of palmitate change during postnatal development and food deprivation in liver, kidney and heart of pigs. J Nutr 127: 1814-1821, 1997.

65. Zeng J, Li D. Expression and purification of his-tagged rat peroxisomal acyl-CoA oxidase I wild-type and E421 mutant proteins. Protein Expr Purif 38: 153-160, 2004.

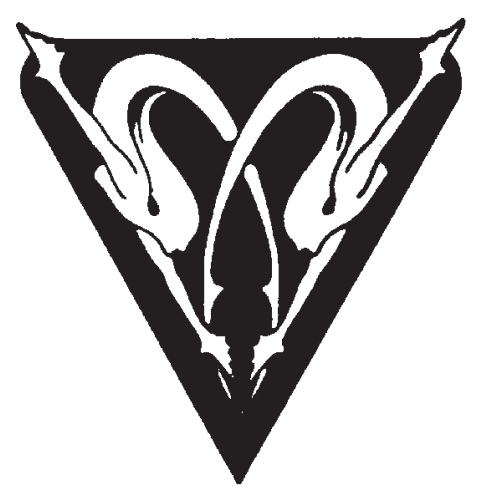

